\title{
A Field Measurement Based Wind Characteristics Analysis of a Typhoon in Near-Ground Boundary Layer
}

\author{
Dandan Xia ${ }^{1,2}$, Liming Dai ${ }^{1,2}$, Li Lin ${ }^{1, *}$, Huaifeng Wang ${ }^{1}$ and Haitao $\mathrm{Hu}^{1}$ \\ 1 Fujian Provincial Key Laboratory of Wind Disaster and Wind Engineering, Xiamen University of Technology, \\ Xiamen 361024, China; xia229@uregina.ca (D.X.); liming.dai@uregina.ca (L.D.); \\ 2014110911@xmut.edu.cn (H.W.); 2013120901@xmut.edu.cn (H.H.) \\ 2 Department of Industrial Systems Engineering, University of Regina, Regina, SK S4S0A2, Canada \\ * Correspondence: 2011110904@xmut.edu.cn
}

check for updates

Citation: Xia, D.; Dai, L.; Lin, L.; Wang, H.; Hu, H. A Field

Measurement Based Wind Characteristics Analysis of a Typhoon in Near-Ground Boundary Layer. Atmosphere 2021, 12, 873. https:// doi.org/10.3390/atmos12070873

Academic Editor: Jimy Dudhia

Received: 28 May 2021

Accepted: 1 July 2021

Published: 5 July 2021

Publisher's Note: MDPI stays neutral with regard to jurisdictional claims in published maps and institutional affiliations.

Copyright: (C) 2021 by the authors. Licensee MDPI, Basel, Switzerland. This article is an open access article distributed under the terms and conditions of the Creative Commons Attribution (CC BY) license (https:/ / creativecommons.org/licenses/by/ $4.0 /)$.

\begin{abstract}
The field measurement was conducted to observe the wind field data of West Pacific typhoon "Maria" in this research. With the application of ultrasonic anemometers installed in different heights $(10 \mathrm{~m}, 80 \mathrm{~m}, 100 \mathrm{~m})$ of the tower, the three dimensional wind speed data of typhoon "Maria" was acquired. In addition, vane-type anemometers were installed to validate the accuracy of the wind data from ultrasonic anemometers. Wind characteristics such as the mean wind profile, turbulence intensity, integral length scale, and wind spectrum are studied in detail using the collected wind data. The relationship between the gust factor and turbulence intensity was also studied and compared with the existing literature to demonstrate the characteristics of Maria. The statistical characteristics of the turbulence intensity and gust factor are presented. The corresponding conclusion remarks are expected to provide a useful reference for designing wind-resistant buildings and structures.
\end{abstract}

Keywords: field measurements; data acquisition; Typhoon Maria; wind characteristics; windresistant design

\section{Introduction}

Numerous wind-sensitive structures such as high-rise buildings and large span bridges have been built in recent years, especially in China, due to the rapid economic increase. It is essential to fully study the wind characteristics for the wind resistant design of these structures. Typhoons are natural hazards that may cause substantial economic losses and pose a threat to life. The average loss in China caused by typhoons is over 200 billion yuan per year. The economic loss was estimated to be 970.7 billion yuan in 1996 and has a growing tendency since then [1]. Researchers have paid much attention to the investigation of typhoons. Specific studies have been conducted via simulation methods, wind tunnel tests, and field measurements. Computational fluid dynamics (CFD) simulations have been proven to be an efficient method compared with experimental methods. This method provides detailed wind field information and can also be well controlled under different terrain and flow conditions. However, due to technology limitations, the accuracy of the simulation results still needs to be verified by wind tunnel tests or field measurements. The wind tunnel test is the most commonly used approach to investigate the influence of wind on buildings and structures. However, it still has limitations such as the lack of consideration of detailed terrain conditions or the selection of structural parameters.

Field measurements have been regarded as the most reliable method that can directly provide real long-term wind data and structural responses even though they are costly and time consuming. Numerous researchers have conducted observations and analyses for strong typhoon processes, and thus, the wind characteristics have been well investigated [2-8]. Wind characteristics such as wind profile, gust factor, and turbulence intensity can be calculated 
in different measurement conditions [9,10]. Moreover, non-stationary methods have also been applied to obtain detailed wind characteristics of typhoons [11-13].

Specifically, gradual increases in wind measurement research have been conducted for tall buildings in China, and significant results have been obtained. The typhoon characteristics and their influence on the wind-induced response on tall buildings have been investigated in detail in Hong Kong [14-16]. For instance, through field wind measurements on a 70-storey tall building in Hong Kong, the wind characteristics of four typhoons were studied, and the typhoon characteristics in the Hong Kong area were discussed [17]. Moreover, to fully study the dynamic response of large span bridges, numerous wind field measurements were performed with installed structural health monitoring systems, which have provided significant recommendations on both the design and construction of long-span bridges [18-21]. Another consideration for wind characteristic analysis is the estimation of wind power due to the increasing demand for renewable energy worldwide. The potential wind energy was studied in specific areas by the long-term record of both typhoon data and monsoon wind data [22-26]. Although many wind field measurements have been performed to explore wind characteristics and wind load on structures, they may show significant differences in different areas due to the features of the terrain. However, currently, few wind field experiments have been conducted in Fujian Province, even though it is typhoon-prone. In this research, to investigate the wind characteristics in southeastern Fujian Province, a wind field measurement system installed in a $100 \mathrm{~m}$ tower was established in Yutou Island, Pingtan County, Fujian Province. By observing the wind data during the typhoon process, the wind characteristics of the typhoon periphery such as the wind profile, turbulence intensity, gust factor, and wind power spectrum are investigated in details.

\section{Measurement System Setup}

\subsection{Experiment Site and Instruments}

The measurement site is located on Yutou Island in Pingtan County in Fujian Province, China, with a latitude of $25^{\circ} 37^{\prime} 56^{\prime \prime} \mathrm{N}$ and longitude of $119^{\circ} 34^{\prime} 45^{\prime \prime} \mathrm{E}$. Because it is surrounded by the sea on the north side, the island has suffered numerous typhoons and contains abundant wind resources. To study the wind characteristics in this area, a $100 \mathrm{~m}$ wind tower was built, as shown in Figure 1. Three 3D sonic anemometers as shown in Figure 2 are installed at heights of $10 \mathrm{~m}, 80 \mathrm{~m}$, and $100 \mathrm{~m}$. The ultrasonic systems have been widely applied in meteorological measurements for their ability to register instantaneous values of the measured characteristics of a turbulent atmosphere with high sampling rates $[27,28]$. In this paper, the $3 \mathrm{D}$ sonic anemometers applied were high-performance Wind Master Pro produced by UK Gill Company with the wind speed range: $0 \sim 65 \mathrm{~m} / \mathrm{s}$, resolution $0.01 \mathrm{~m} / \mathrm{s}$, wind direction range: $0 \sim 359^{\circ}$, resolution: $0.1^{\circ}$. A $10 \mathrm{~Hz}$ sample output frequency was used on site, indicating that one set of $3 \mathrm{D}$ instantaneous wind speed was recorded per $0.1 \mathrm{~s}$. The ultrasonic anemometers can work at temperatures of $-40 \sim+70{ }^{\circ} \mathrm{C}$, and a small weather station was installed at a $10 \mathrm{~m}$ height to monitor the working temperature of the ultrasonic anemometers with an accuracy of the thermometer of $0.01{ }^{\circ} \mathrm{C}$. Identification codes are generated automatically to be used as the reference for data quality control. When the data are unstable or out of the range, it will be diagnosed as 0 in the recorded data. The bad or invalid data points will be eliminated and then made up by the multiple truncation variance data control method [29]. To ensure the accuracy of the 3D sonic anemometer data, six vane-type anemometers, as shown in Figure 3, were installed at heights of $10 \mathrm{~m}, 30 \mathrm{~m}, 50 \mathrm{~m}, 80 \mathrm{~m}, 90 \mathrm{~m}$, and $100 \mathrm{~m}$, as shown in Figure 1 . The distance between the wind tower and anemometers was $1.5 \mathrm{~m}$ to eliminate the influence of the tower. The data acquisition system was located at a height of $6 \mathrm{~m}$ for data collection. To demonstrate the wind characteristics in detail, the terrain in four directions around the measurement is presented in Figure 4. 


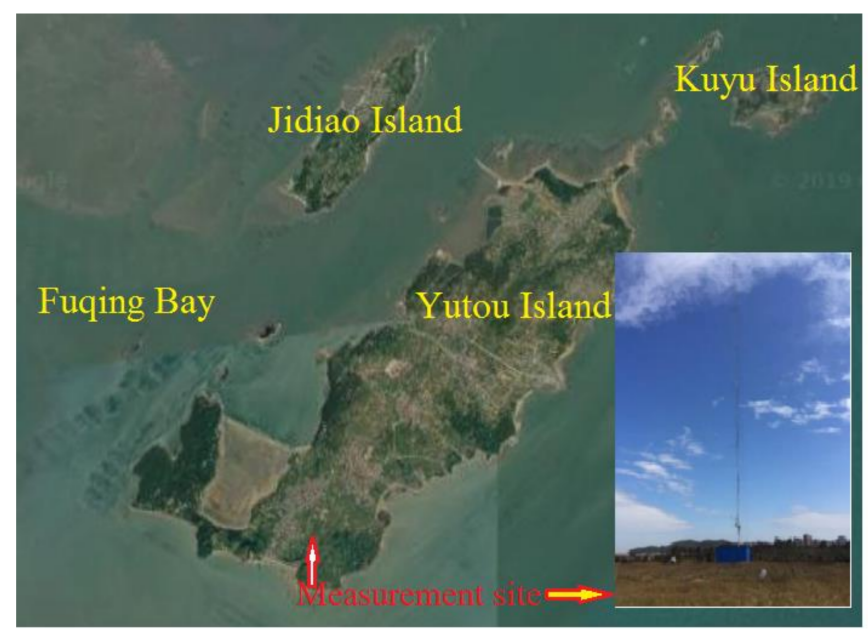

Figure 1. Location of the measurement site.

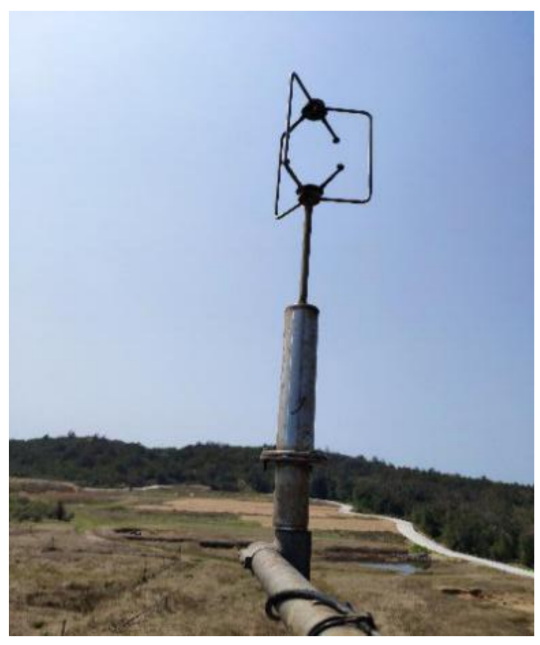

Figure 2. Sonic anemometers.

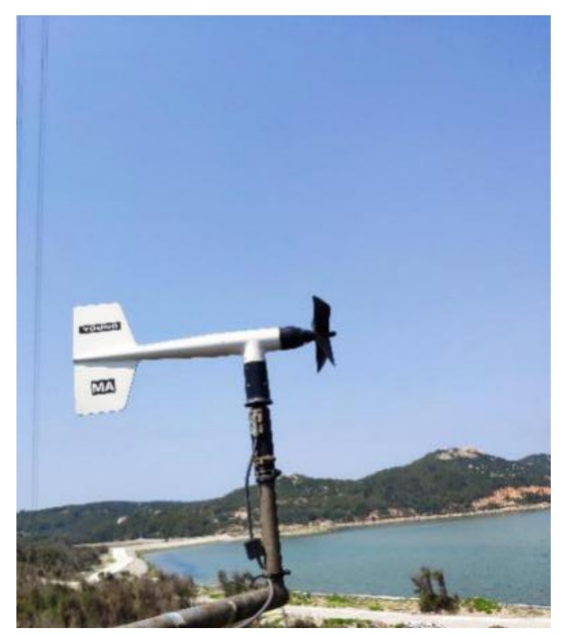

Figure 3. Vane type anemometer. 

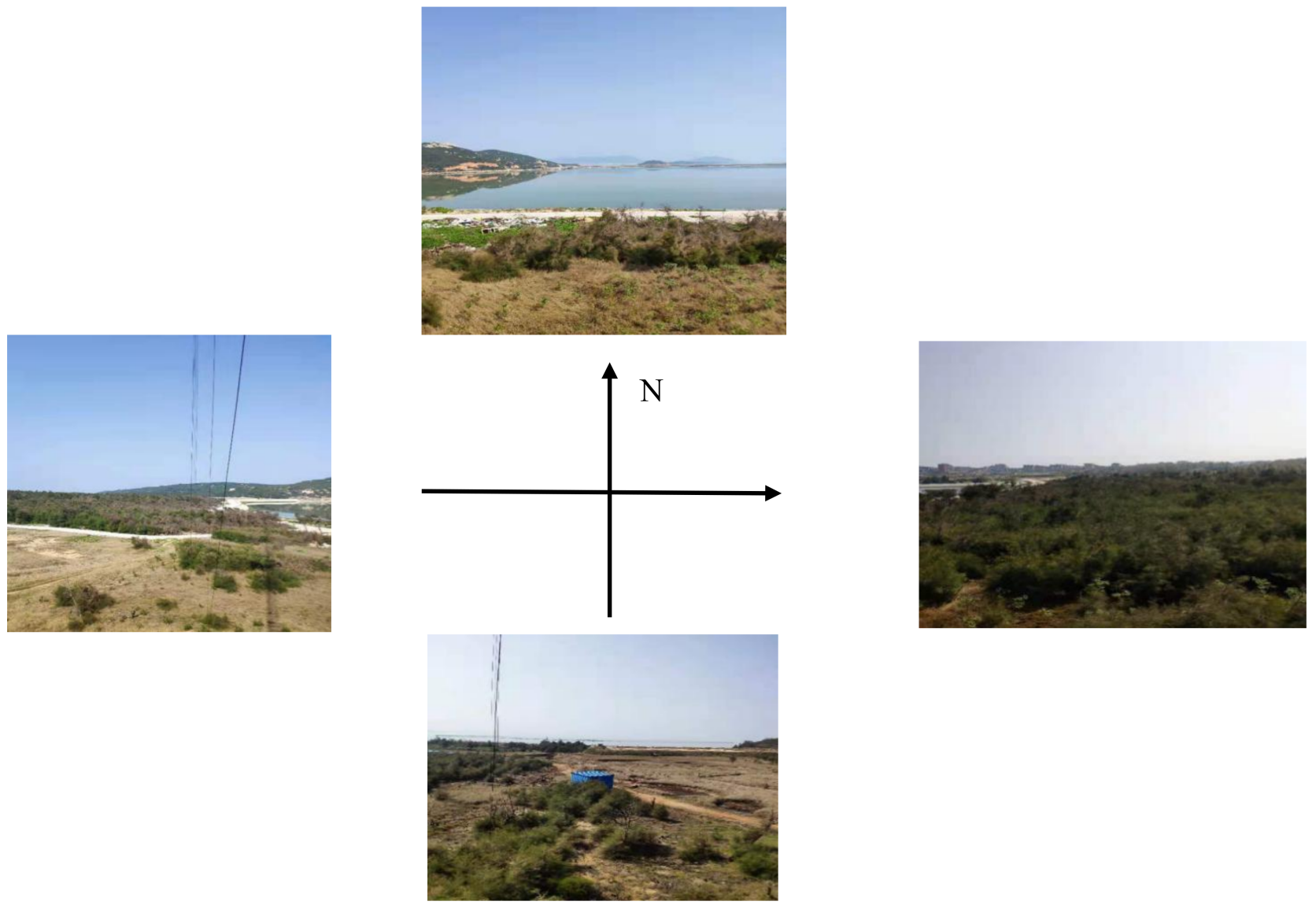

Figure 4. Photos of the terrain around the measurement station.

\subsection{Description of the Typhoon "Maria"}

The eighth typhoon in 2018, "Maria", appeared on the northwest Pacific Ocean surface approximately $1930 \mathrm{~km}$ east of Yilan County, Taiwan Province, at a super typhoon level. The typhoon landed on Lianjiang, Huangqi Peninsula, Fujian Province, China, at 09:10, 11 July, with a maximum wind speed of $42 \mathrm{~m} / \mathrm{s}$, a central minimum pressure of $960 \mathrm{hPa}$, and moved toward the northwest at a speed of $15 \mathrm{~km} / \mathrm{h}$. The measurement site was approximately $83.61 \mathrm{~km}$ away from the typhoon landing center. The landing path and measurement site are shown in Figure 5.

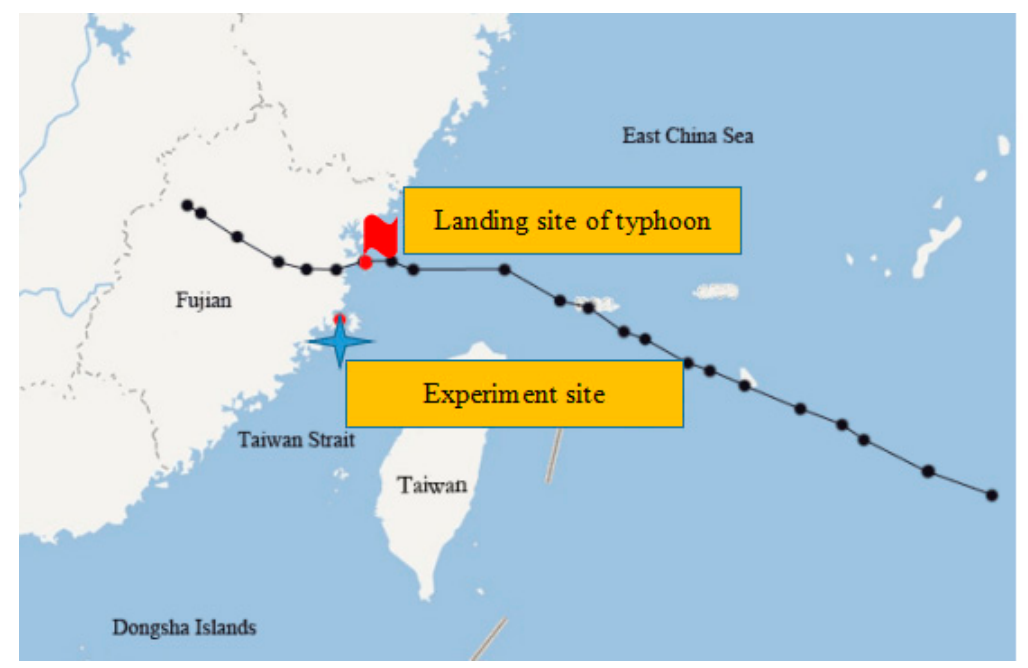

Figure 5. The path of Typhoon "Maria". 


\section{Near-Ground Wind Characteristics of the Typhoon}

The record of Typhoon "Maria" was from 0:00 to 24:00 on 11 July 2018, with a duration of $24 \mathrm{~h}$ data. Samples were divided every $10 \mathrm{~min}$ [30] based on the standard time interval in China. The installed ultrasonic anemometer can automatically distinguish the invalid data caused by rainfall. Moreover, to ensure the accuracy of wind data, samples were selected according to the selected criterion, and only the samples with $98 \%$ validation data could be used for the wind characteristic analysis. The data were low pass filtered at $4 \mathrm{~Hz}$ to eliminate aliasing caused by high sampling frequency. Due to the high sampling frequency of the ultrasonic anemometer, the recorded wind speed data may include some bad or invalid data. The multiple truncation variance method was applied to smoothly estimate the original data as follows:

First, calculate the time series difference as $d u(t)$ as:

$$
d u(t)=u(t+2)-u(t)
$$

where $u(t)$ is the $t$ th time point of the wind speed data. The mean value of $d u(t)$ and $d u^{2}$ can be expressed as:

$$
\overline{d u}=\frac{1}{n-2} \sum_{i=1}^{n-2} d u(t), \overline{d u^{2}}=\frac{1}{n-2} \sum_{i=1}^{n-2} d u(t)^{2}
$$

The truncation variance can be expressed as follows:

$$
\sigma^{2}=\overline{d u^{2}}-\overline{d u}^{2}
$$

The criterion to detect invalid data can be defined as:

$$
\Delta=c \cdot \sigma
$$

In which, $c$ is the coefficient to determine unreasonable data. In this research, $c$ is taken as 4 , indicating that when the absolute value of difference between the mean value of the sample and the total sample was greater than four times the standard deviation, the data will be diagnosed as invalid data. When the invalid data are detected, it will be modified by the five-point interpolation method [29].

\subsection{Mean Wind Data}

The $10 \mathrm{~min}$ wind speed and wind direction measured by three sonic anemometers are indicated in Figures 6 and 7 with the distance of the typhoon center to the measurement site. The blue line is the time point when Typhoon "Maria" made landfall. As accepted by researchers, extreme winds in the eyewall regions of typhoons may cause serious damage to buildings and structures. The wind speed time history shows an ' $\mathrm{M}$ ' shape with double peaks, which means the typhoon wind circle passed through the measurement site. The distance shows that the typhoon center first got close to the measurement site and then got far way. When the typhoon wind circle arrived, the wind speed reached a peak, and when it passed by, the wind speed reached the other peak. This " $M$ " type indicates that the measured wind speed can represent the wind characteristic of the periphery of Typhoon "Maria". In Figure 6, the wind speed increases as the measured height increases, showing consistent varying tendencies for different heights. The maximum mean wind speed reached $26.13 \mathrm{~m} / \mathrm{s}$ during the landing of a typhoon. The change in the wind direction during the typhoon process was approximately $160^{\circ}$. To ensure the validity of the measured data, the $10 \mathrm{~min}$ average wind speed at a height of $10 \mathrm{~m}$ obtained from the vane-type anemometer and sonic anemometer were compared, as shown in Figure 8. The wind speed data acquired by the two types of anemometers agreed well, which indicates the reliability of the obtained wind data. 


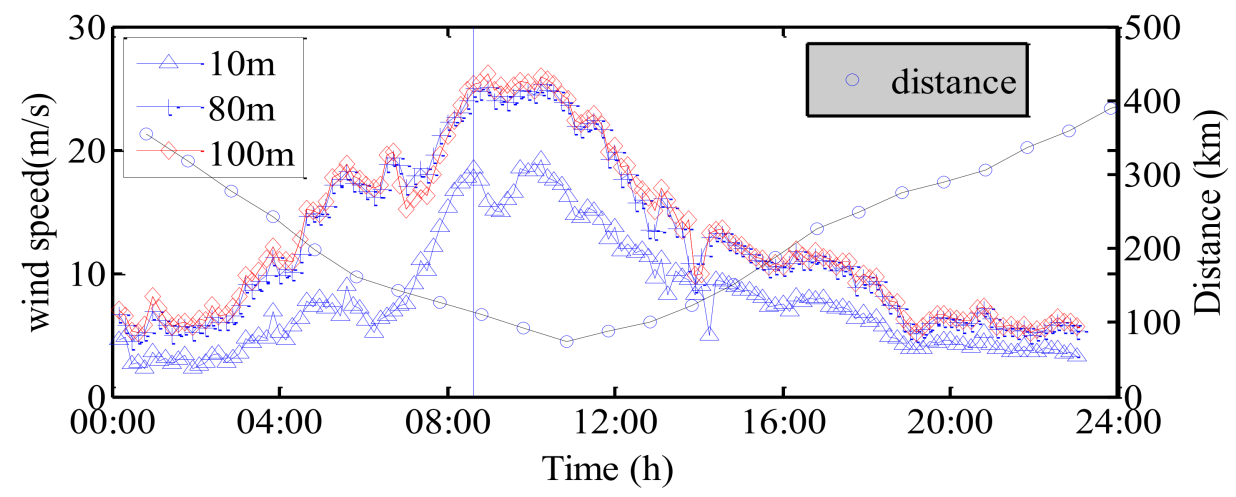

Figure 6. The 10-min mean wind speed during Typhoon "Maria".

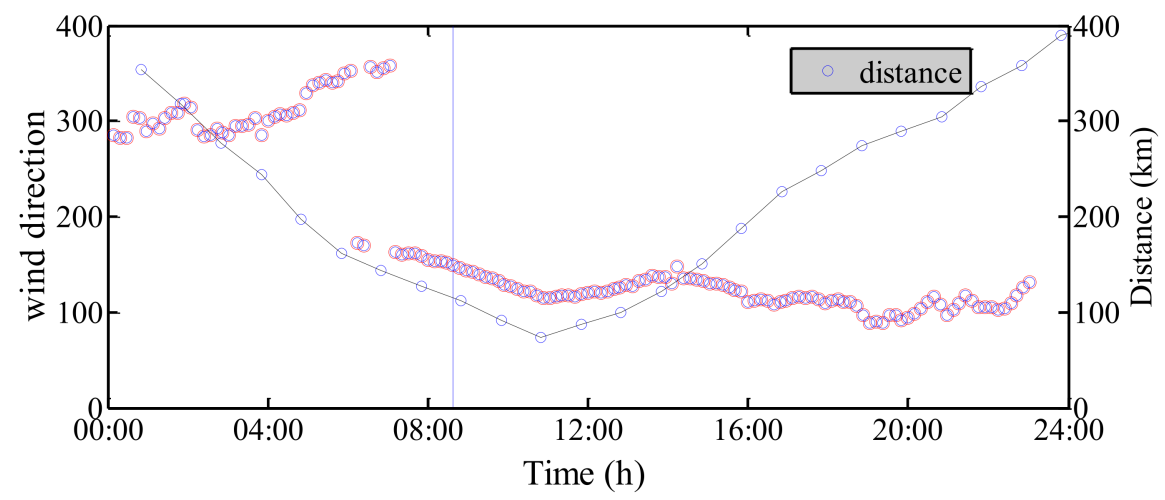

Figure 7. The mean wind direction during Typhoon "Maria".

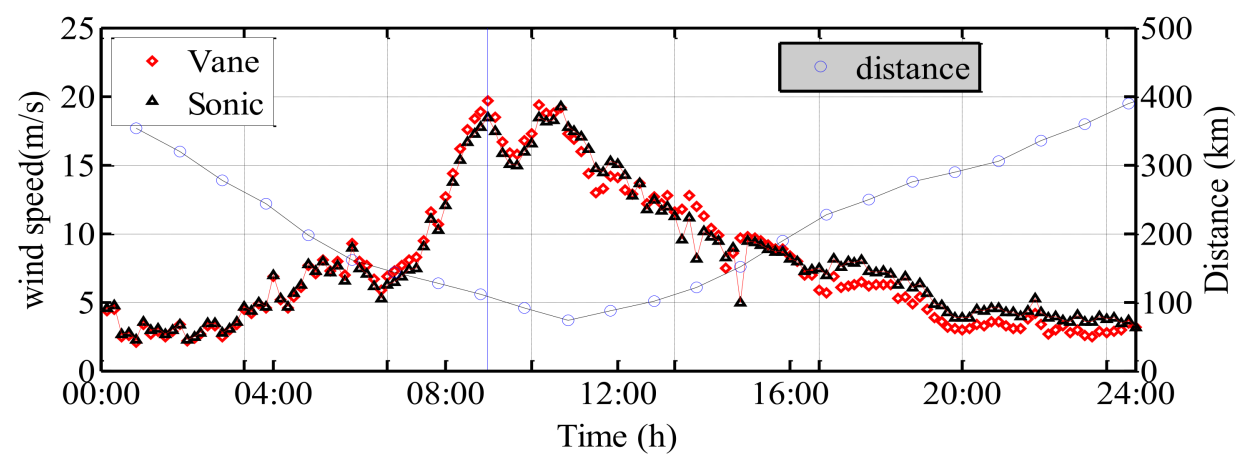

Figure 8. Comparison of the $10 \mathrm{~min}$ wind speed from a vane anemometer and a sonic anemometer.

\subsection{Fluctuating Wind Data}

In this experiment, the output data can be time series $t$, and the wind speeds in three directions are $u_{x}, u_{y}$, and $u_{z}$. Taking $10 \mathrm{~min}$ as the statistical interval, the average speed can be expressed as follows:

$$
\begin{gathered}
U=\sqrt{{\overline{u_{x}}}^{2}+{\overline{u_{y}}}^{2}} \\
\phi=-\operatorname{sgn}\left(\overline{u_{y}}\right) \cdot \arccos \frac{\overline{u_{x}}}{U} \cdot 180^{\circ} / \pi+180^{\circ}
\end{gathered}
$$

where $\bar{u}_{x}, \bar{u}_{y}$ are the mean wind speeds in the directions of $x$ and $y$, respectively. The fluctuating wind speeds of the longitudinal, horizontal, and vertical wind speeds can be expressed as follows:

$$
\begin{gathered}
u^{\prime}(t)=u(t) \cos \phi+v(t) \sin \phi-u \\
v^{\prime}(t)=-u(t) \sin \phi+v(t) \cos \phi
\end{gathered}
$$




$$
w^{\prime}(t)=w(t)-W
$$

where $u^{\prime}(t), v^{\prime}(t)$, and $w^{\prime}(t)$ are the fluctuating wind speeds in the longitudinal, horizontal, and vertical directions, respectively. Figure 9 indicates the fluctuating wind speed at a $10 \mathrm{~m}$ height during Typhoon Maria.

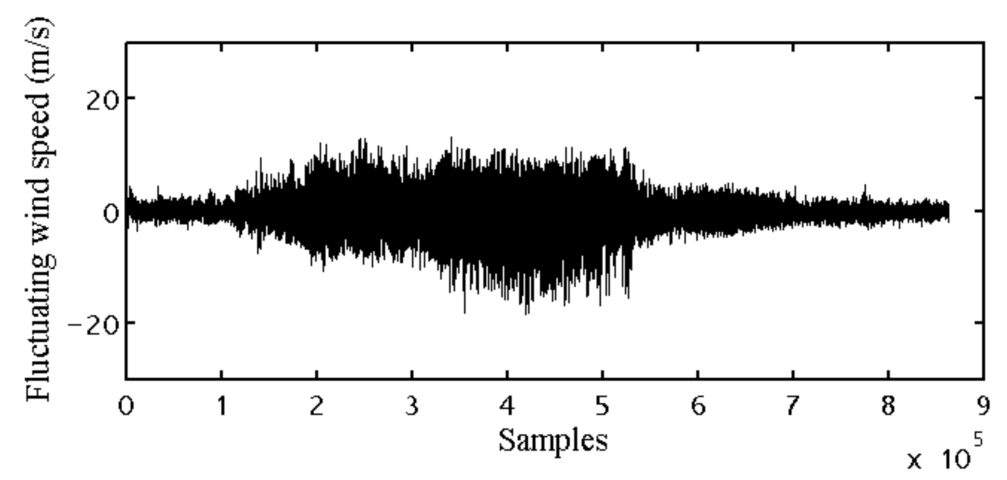

Figure 9. Fluctuating wind speed during Typhoon Maria.

\section{Wind Characteristic Analysis}

\subsection{Mean Wind Characteristics}

The wind profile is an essential parameter to describe wind characteristics in a neutrally stable atmospheric boundary layer. The power law (recommended in Code GB5009-2001) and logarithmic law are usually used in wind profile analysis. The power law can be expressed as follows:

$$
u(z)=u_{1}\left(\frac{z}{z_{1}}\right)^{\alpha}
$$

where $z_{1}$ is the reference height, which is considered to be $10 \mathrm{~m} ; u(z)$ is the wind speed at height $z$; and $\alpha$ is the wind profile parameter.

The wind profile of the measurement site was calculated based on the power law equation. Based on the measured data, the mean wind profile parameter was calculated as 0.2208 , which was close to the recommended value of class $C$ ground motion in the Chinese Code. This finding may be caused by the terrain of the measurement site. Even though the north side of the measurement site is close to sea, the south side is faced with trees, as shown in Figure 6. From Figure 9, the main direction of this typhoon is approximately the southeast direction; therefore, the roughness of the forest may slow down the wind speed. Figure 10 shows the wind profile parameters with wind speed. It is obvious that the wind profile parameter decreases as the wind speed increases. The main reason for this phenomenon may be that the wind profile coefficient is to show the influence of ground roughness in the wind speed; with the wind speed increase, the influence of ground roughness decreases, therefore, the wind profile coefficient also decreases. Figure 11 shows the wind profiles for different wind speeds during Typhoon "Maria", indicating that the wind profile significantly varies with the wind speed.

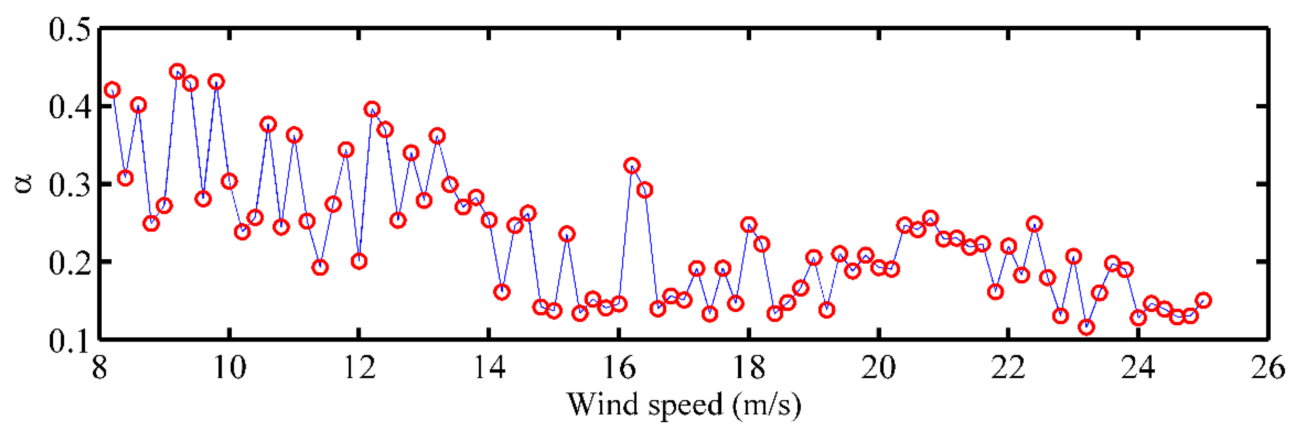

Figure 10. Wind profile parameters with different wind speeds. 


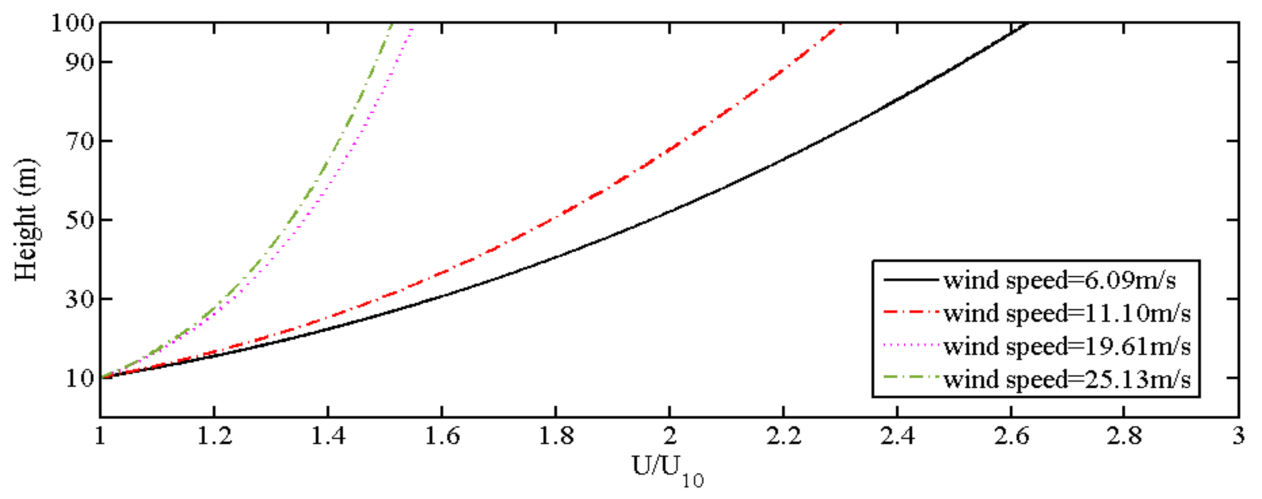

Figure 11. Wind profile parameters with different wind speeds.

\subsection{Fluctuating Wind Characteristics}

4.2.1. Turbulence Intensity

$$
I_{i}=\frac{\sigma_{i}}{U}, i=u, v, w
$$

where $\sigma_{i}$ is the mean variance of the fluctuating wind speed and $U$ is the mean wind speed in the statistical time interval of $10 \mathrm{~min}$.

Figure 12 shows the turbulence intensity at $10 \mathrm{~m}$ in the longitudinal, horizontal, and vertical directions. The blue circles indicate the distance between typhoon center and measurement site. Compared with the horizontal and longitudinal directions, the vertical direction showed a smaller turbulence intensity and hardly changed during the typhoon. Figure 13 shows the turbulence intensity in the three directions via the wind speed. As indicated, the turbulence intensity decreased with increasing longitudinal and horizontal directions. However, the turbulence intensity remained almost unchanged in the vertical direction.

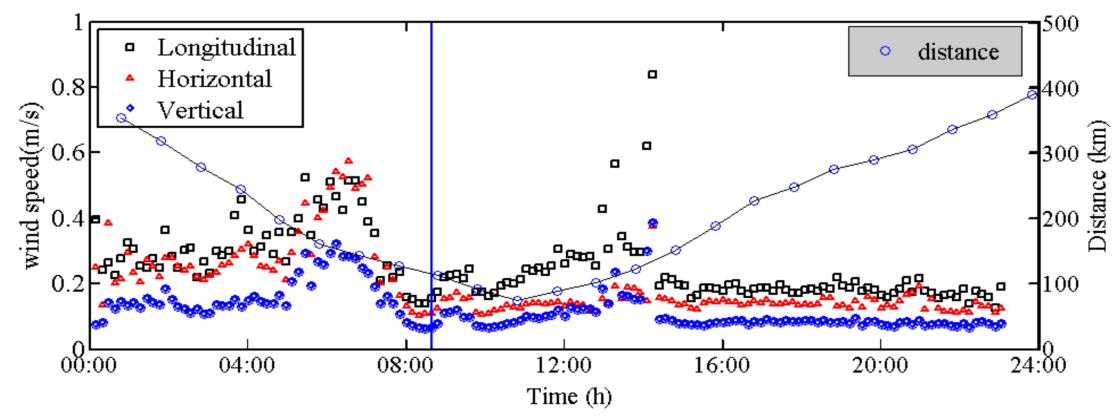

Figure 12. Measured turbulence intensity.

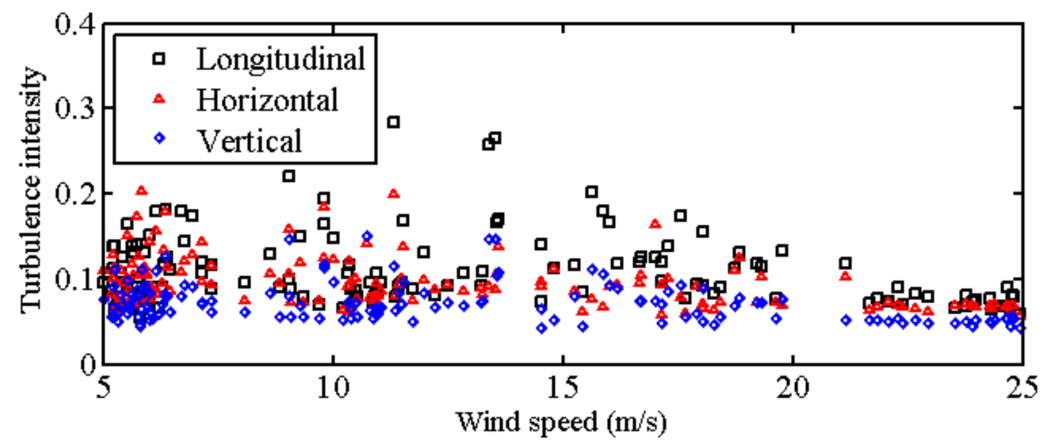

Figure 13. Measured turbulence intensity via wind speed. 
Table 1 shows a summary of the measured turbulence intensities during Typhoon "Maria". The turbulence intensity decreases as the height increases. The ratios of the turbulence intensities $I_{u}: I_{v}: I_{w}$ at $10 \mathrm{~m}, 80 \mathrm{~m}$, and $100 \mathrm{~m}$ are 1:0.76:0.47, 1:0.86:0.63, and 1:0.89:0.50, respectively. With increasing height, the ratio of the vertical direction increases. The measured turbulence intensity ratio $I_{u}: I_{v}: I_{w}$ at a height of $100 \mathrm{~m}$ is close to that recommended in the Chinese wind-resistant code $I_{u}: I_{v}: I_{w}=1: 0.88: 0.5$. However, the data showed a difference at heights of $10 \mathrm{~m}$ and $80 \mathrm{~m}$, which indicates the difference in wind characteristics between typhoons and seasonal winds, which is the basis of recommendation in the Chinese code.

Table 1. Summary of the measured turbulence intensities.

\begin{tabular}{ccccc}
\hline Wind Field & Measured & $\mathbf{1 0 ~} \mathbf{~}$ & $\mathbf{8 0 ~} \mathbf{~}$ & $\mathbf{1 0 0} \mathbf{~ m}$ \\
\hline & Mean & 0.2549 & 0.1116 & 0.1043 \\
Typhoon & Maximum & 0.5378 & 0.2834 & 0.2943 \\
"Maria" & Minimum & 0.1265 & 0.0543 & 0.0503 \\
& Standard deviation & 0.1101 & 0.0405 & 0.0345 \\
& $I_{u}: I_{v}: I_{w}$ & $1: 0.76: 0.47$ & $1: 0.86: 0.63$ & $1: 0.89: 0.50$ \\
\hline
\end{tabular}

The generalized extreme value (GEV) distribution has been proven to be an efficient distribution developed from extreme value theory that combines the Gumbel, Fréchet, and Weibull functions. The general probability density function of the GEV can be written as follows:

$$
\begin{gathered}
f(x ; \mu ; \sigma ; k)=\frac{1}{\sigma} \exp \left(-\left(1+\gamma \cdot \frac{x-\mu}{\sigma}\right)^{-\frac{1}{k}}\right)\left(1+\gamma \cdot \frac{x-\mu}{\sigma}\right)^{-1-\frac{1}{k}} ; k \neq 0 \\
f(x ; \mu ; \sigma ; 0)=\frac{1}{\sigma} \exp \left(-\exp \left(\frac{x-\mu}{\sigma}\right)-\frac{x-\mu}{\sigma}\right) ; k=0
\end{gathered}
$$

where $k, \sigma$, and $\mu$ are the shape, scale, and location parameters, respectively. When $k=0$, the distribution is regarded as the type I case (Gumbel distribution), with $k>0$ and $k<0$, and the distribution is referred to as the Type II (Frechet distribution) case and Type III (Weibull distribution) case, respectively. The turbulence intensity during this typhoon process is fitted by the GEV distribution by maximum likelihood estimates with a $95 \%$ confidence, and the corresponding probability density function is shown in Figure 14.
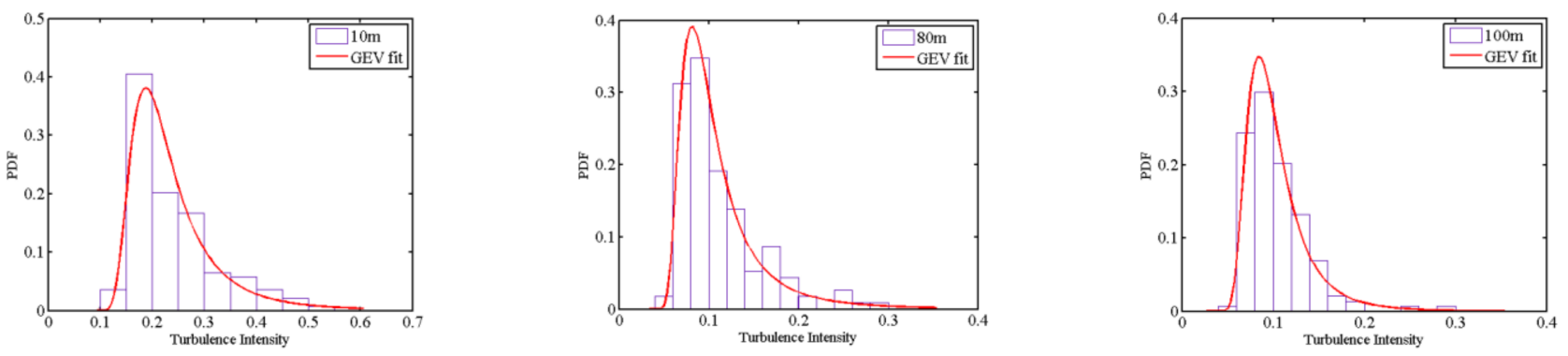

Figure 14. Turbulence intensity fitted by the GEV distribution.

The coefficients fitted by the GEV distribution are listed in Table 2 including the statistical characteristics such as the mean, median standard deviation, skewness, and kurtosis. To verify the accuracy of the fitting results, goodness-of-fit tests such as the Kolmogorov-Smirnov (K-S) test and the Anderson-Darling (A-D) test are conducted with a $95 \%$ confidence. It can be seen from the table that the shape values for the three heights were all above 0 , indicating that the fitted distributions were Type II cases. This finding means that the turbulence intensity during Typhoon "Maria" can be described by the 
Freche distribution. From Table 2, it can be seen that all skewness coefficients were positive, indicating that distributions at each height were right-skewed or right-tailed. All kurtosis values were greater than 3.0, indicating that all distributions of Iu are leptokurtic and more peaked than a normal distribution with longer tails. Meanwhile, both the skewness and kurtosis coefficient have a tendency of decrease from $10 \mathrm{~m}$ to $80 \mathrm{~m}$ and decrease from $80 \mathrm{~m}$ to $100 \mathrm{~m}$. The results show differences in the literature [31], in which the turbulence intensity agreed well with the Weibull distribution based on the observation of typhoons in Zhejiang Province, indicating the distinctive features of typhoons. Moreover, it is also due to the unique features of typhoons, the observation of typhoons, and analysis of typhoon characteristics are essential for the wind-resist design of a specific area.

Table 2. Statistic results of the turbulence intensities.

\begin{tabular}{ccccccccc}
\hline Height & Mean & Median & Std. & Skewness & Kurtosis & $\boldsymbol{k}$ & $\boldsymbol{\sigma}$ & $\boldsymbol{\mu}$ \\
\hline $10 \mathrm{~m}$ & 0.2549 & 0.2183 & 0.1101 & 1.9748 & 8.4317 & 0.3183 & 0.0529 & 0.1994 \\
$80 \mathrm{~m}$ & 0.1116 & 0.9050 & 0.0405 & 1.5459 & 5.4669 & 0.3198 & 0.0245 & 0.0879 \\
$100 \mathrm{~m}$ & 0.1043 & 0.9069 & 0.0345 & 1.9002 & 9.3747 & 0.1556 & 0.0214 & 0.0876 \\
\hline
\end{tabular}

It has been widely accepted in the literature that the turbulence intensity decreases with increasing wind speed [31]. Tables 3-5 indicate the statistical value of the turbulence intensity at $10 \mathrm{~m}, 80 \mathrm{~m}$, and $100 \mathrm{~m}$, with classification by the wind speed. The mean value of the turbulence intensity decreases with the wind speed at all three heights, which agrees with the literature and previous descriptions. Moreover, the variances of the three directions at heights of $10 \mathrm{~m}, 80 \mathrm{~m}$, and $90 \mathrm{~m}$ decrease with increasing wind speed, which agrees with [31].

Table 3. Statistical value of the wind turbulence intensity (10 m).

\begin{tabular}{ccccccc}
\hline \multirow{2}{*}{$\begin{array}{c}\text { Wind } \\
\text { Speed }\end{array}$} & \multicolumn{2}{c}{$\boldsymbol{I}_{\boldsymbol{u}}$} & \multicolumn{2}{c}{$\boldsymbol{I}_{\boldsymbol{v}}$} & \multicolumn{2}{c}{$\boldsymbol{I}_{\boldsymbol{w}}$} \\
\cline { 2 - 7 } & Mean Value & Variance & Mean Value & Variance & Mean Value & Variance \\
\hline $\mathrm{U}<15 \mathrm{~m} / \mathrm{s}$ & 0.2671 & 0.0843 & 0.2083 & 0.0504 & 0.1281 & 0.0206 \\
$\mathrm{U}>15 \mathrm{~m} / \mathrm{s}$ & 0.1939 & 0.0388 & 0.1275 & 0.0165 & 0.0830 & 0.0071 \\
\hline
\end{tabular}

Table 4. Statistic value of the wind turbulence intensity $(80 \mathrm{~m})$.

\begin{tabular}{ccccccc}
\hline \multirow{2}{*}{$\begin{array}{c}\text { Wind } \\
\text { Speed }\end{array}$} & \multicolumn{2}{c}{$\boldsymbol{I}_{\boldsymbol{u}}$} & \multicolumn{2}{c}{$\boldsymbol{I}_{\boldsymbol{v}}$} & \multicolumn{2}{c}{$\boldsymbol{I}_{\boldsymbol{w}}$} \\
\cline { 2 - 7 } & Mean Value & Variance & Mean Value & Variance & Mean Value & Variance \\
\hline $\mathrm{U}<15 \mathrm{~m} / \mathrm{s}$ & 0.1185 & 0.0164 & 0.1067 & 0.0124 & 0.0763 & 0.0064 \\
$\mathrm{U}>15 \mathrm{~m} / \mathrm{s}$ & 0.0986 & 0.0109 & 0.0778 & 0.0064 & 0.0609 & 0.0040 \\
\hline
\end{tabular}

Table 5. Statistical value of the wind turbulence intensity (100 m).

\begin{tabular}{ccccccc}
\hline \multirow{2}{*}{$\begin{array}{c}\text { Wind } \\
\text { Speed }\end{array}$} & \multicolumn{2}{c}{$\boldsymbol{I}_{\boldsymbol{u}}$} & \multicolumn{2}{c}{$\boldsymbol{I}_{\boldsymbol{v}}$} & \multicolumn{2}{c}{$\boldsymbol{I}_{\boldsymbol{w}}$} \\
\cline { 2 - 7 } & Mean Value & Variance & Mean Value & Variance & Mean Value & Variance \\
\hline $\mathrm{U}<15 \mathrm{~m} / \mathrm{s}$ & 0.1105 & 0.0137 & 0.1014 & 0.0110 & 0.0576 & 0.0035 \\
$\mathrm{U}>15 \mathrm{~m} / \mathrm{s}$ & 0.0940 & 0.0094 & 0.0782 & 0.0066 & 0.0456 & 0.0022 \\
\hline
\end{tabular}

\subsubsection{Gust Factor and Peak Factor}

The gust factor is a significant feature of fluctuating wind that describes the proportions of the gust wind speed to the mean wind speed. This factor is defined as the ratio of the maximum mean wind speed during gust duration $t_{s}$. In the Chinese structural design 
code, the gust duration is also recommended as $3 \mathrm{~s}$. The expression of the gust factor can be described as follows:

$$
G_{u}\left(t_{s}\right)=1+\frac{\bar{u}\left(t_{s}\right)_{\max }}{U}, G_{v}\left(t_{s}\right)=1+\frac{\bar{v}\left(t_{s}\right)_{\max }}{U}, G_{w}\left(t_{s}\right)=1+\frac{\bar{w}\left(t_{s}\right)_{\max }}{U}
$$

where $\bar{u}\left(t_{s}\right)_{\max }, \bar{v}\left(t_{s}\right)_{\max }$, and $\bar{w}\left(t_{s}\right)_{\max }$ are the longitudinal, horizontal, and vertical maximum average wind speeds, respectively, within the time interval $t_{s}$.

The gust factor may be considerably affected by the measurement height, ground roughness, and time interval. In China, the time interval $t_{s}$ is recommended as $3 \mathrm{~s}$ by wind engineers to calculate the gust factor. Figure 15 shows the gust factor at heights of $10 \mathrm{~m}$, $80 \mathrm{~m}$, and $100 \mathrm{~m}$ with a time interval of $3 \mathrm{~s}$. The gust factor decreases with increasing height. The same conclusion can also be seen in the statistical characteristics analysis in Table 6. Analogous to the turbulence intensity, the GEV distribution was applied to fit the gust factors at the three heights. The corresponding fitted results are shown in Figure 16. As obtained in Table 6, for the height of $10 \mathrm{~m}$, the fitted shape values were all larger than 0 , indicating the Type II cases for the three heights, showing agreement with the turbulence intensity. However, the shape values at $80 \mathrm{~m}$ and $100 \mathrm{~m}$ approached 0 , indicating a type I case (Gumbel distribution) for the gust factors. It should be mentioned that, in Figure 14, outlier data occurred around 14:00, and the same phenomenon could also be found in the plot of turbulence intensity shown in Figure 11. From the wind speed time history, the wind speed significantly decreased around 14:00, which may be one of the reasons for the significant increase in turbulence intensity and gust factors. This also agrees with the conclusion that the turbulence intensity and gust factor decrease with the increase of wind speed (Figure 13). Moreover, the wind direction changed around $20^{\circ}$ at the time segment around 14:00, which induced the fluctuation of the wind speed. Therefore, the fluctuations of wind speed and wind direction result in the outlier data in turbulence intensity and gust factor.
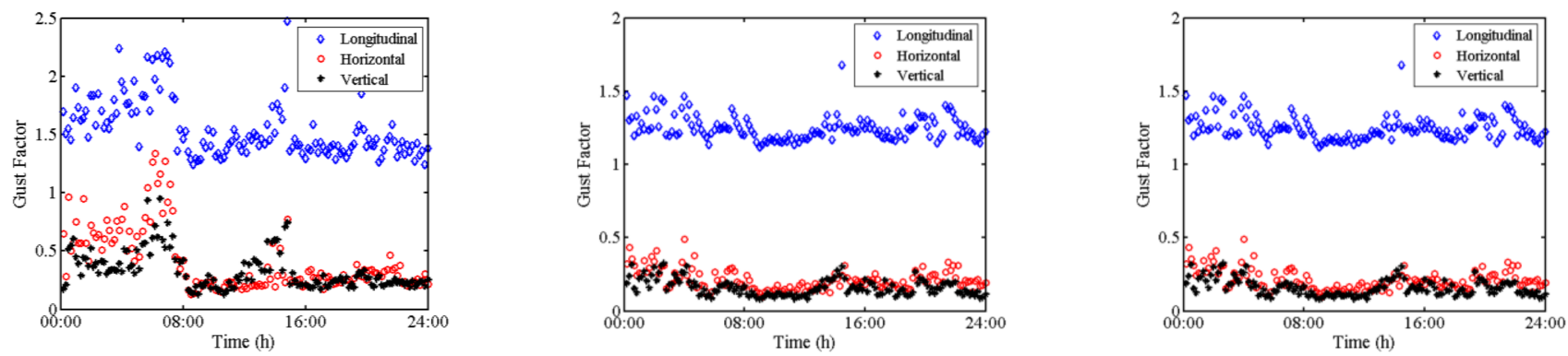

Figure 15. Gust factor at different heights $(10 \mathrm{~m}, 80 \mathrm{~m}, 100 \mathrm{~m})$.

Table 6. Statistical results of the gust factor.

\begin{tabular}{ccccccccc}
\hline Height & Mean & Median & Std. & Skewness & Kurtosis & $\boldsymbol{k}$ & $\boldsymbol{\sigma}$ & $\boldsymbol{\mu}$ \\
\hline $10 \mathrm{~m}$ & 1.5485 & 1.4578 & 0.2480 & 1.3241 & 4.3442 & 0.2846 & 0.1378 & 1.4171 \\
$80 \mathrm{~m}$ & 1.2585 & 1.2407 & 0.0984 & 1.0522 & 4.0255 & 0.0620 & 0.0698 & 1.2110 \\
$100 \mathrm{~m}$ & 1.2500 & 1.2345 & 0.0846 & 1.4960 & 6.8874 & 0.0448 & 0.0578 & 1.2108 \\
\hline
\end{tabular}



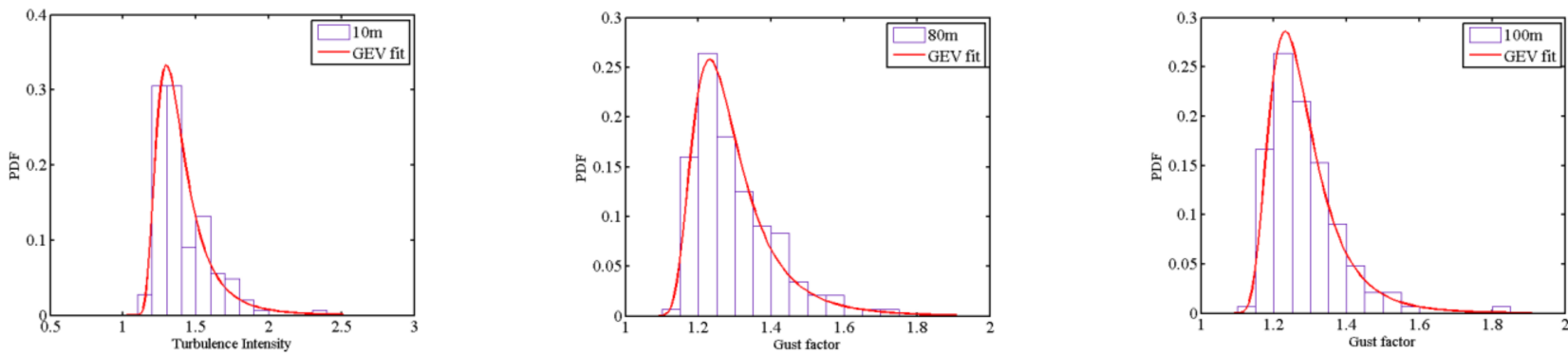

Figure 16. Gust factor fitted by the GEV distribution.

The time interval has proven to be an important aspect in calculating gust factors. In the Chinese Code, the gust factor is usually recommended as 3 s. In Figure 17, gust factors at different time intervals are presented. It can be seen that the gust factor decreases as the time interval increases. The calculated gust factor was far smaller at a time interval of $1 \mathrm{~min}$ than $3 \mathrm{~s}$. Figure 17 shows the mean gust factors under time intervals of 1-60 s. The gust factor shows a linear relation with the logarithm of the time interval in both the longitudinal, horizontal, and vertical directions, as indicated in Figure 18.

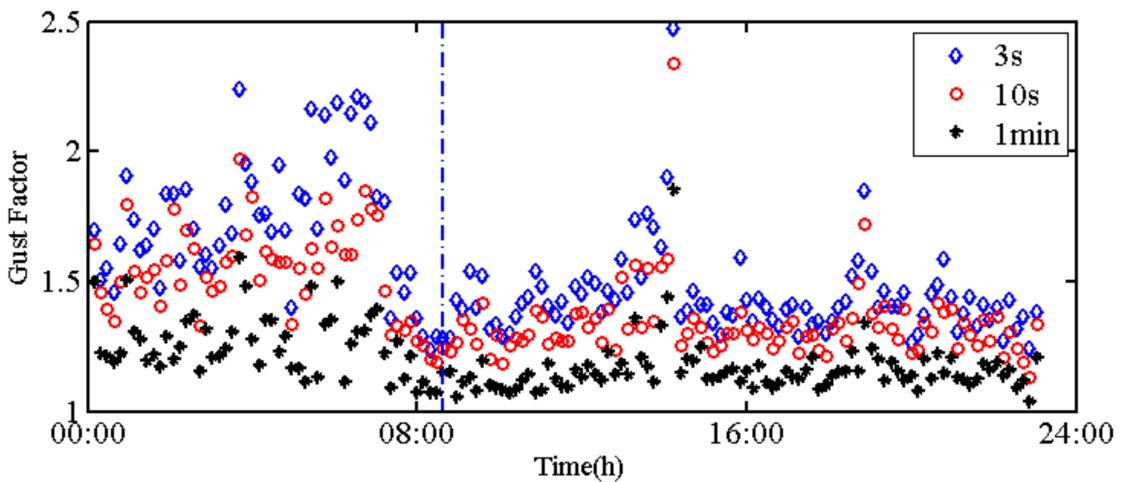

Figure 17. Gust factor at different time intervals.

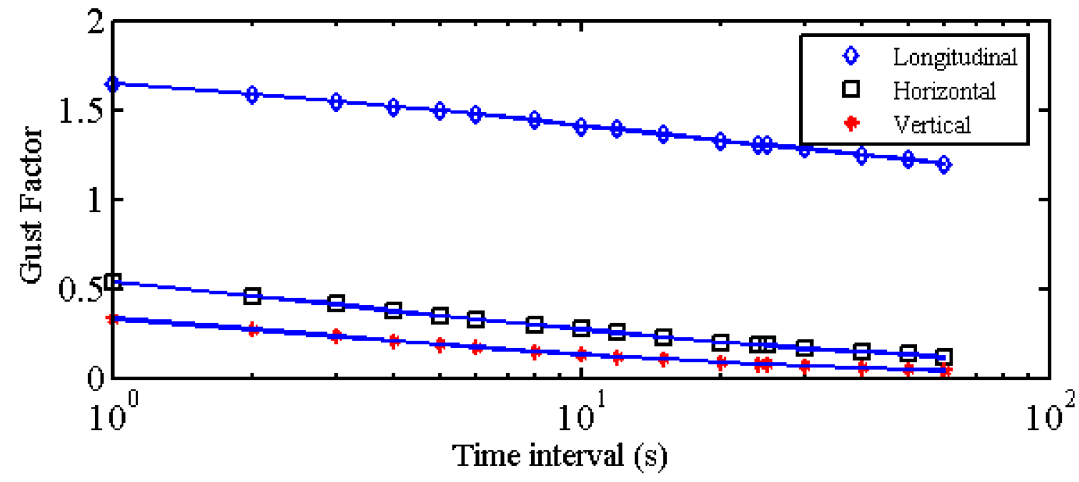

Figure 18. Mean gust factor at different time intervals.

The relationship between the turbulence intensity and the gust factor has attracted attention in wind engineering. However, as discussed previously, the gust factor can be affected by the time intervals. Therefore, based on the measured results, the relation between the turbulence intensity and gust factor can be expressed as follows [32]:

$$
G_{u}\left(t_{s}\right)=1+k_{1} I_{u}^{k_{2}} \ln \frac{T}{t_{s}}
$$


where $G_{u}\left(t_{s}\right)$ is the longitudinal gust factor at time interval $t_{s} ; \mathrm{T}$ is the basic time interval when calculating the mean wind speed, which is $10 \mathrm{~min}$ in this research; and $k_{1}$ and $k_{2}$ are the coefficients at $t_{s}$. The values of $k_{1}$ and $k_{2}$ were suggested by Ishizaki [33] as $k_{1}=0.5 ; k_{2}=1.0$, by Choi [34] as $k_{1}=0.62 ; k_{2}=1.27$, and by Cao [35] as $k_{1}=0.5 ; k_{2}=1.15$. Based on the observed experimental data, $k_{1}$ and $k_{2}$ were fitted as $k_{1}=0.3695 ; k_{2}=0.9224$ as fitted in Figure 19, which showed significant differences from the results in the existing literature.

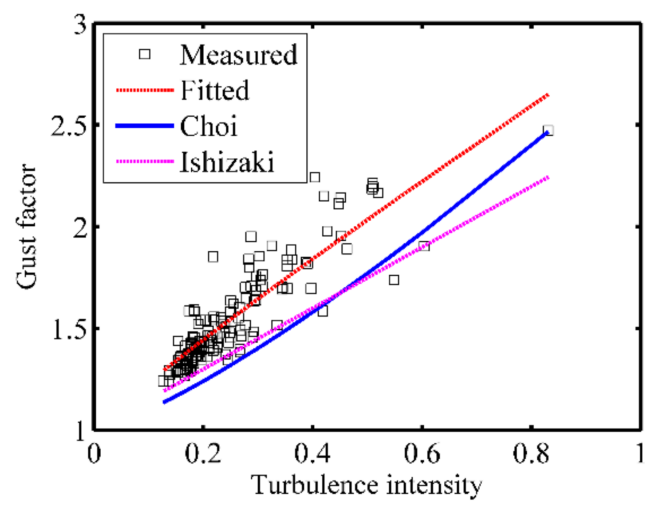

Figure 19. Relationship between the turbulence intensity and the gust factor.

The peak factor is also a feature of the fluctuating wind that describes the ratio of the maximum wind speed fluctuation in time interval $t_{s}$ to the standard deviation of the fluctuating wind speed, expressed as:

$$
g_{u}\left(t_{s}\right)=\frac{\max \left(u\left(t_{s}\right)\right)}{\sigma_{u}}=\frac{\max \left(\hat{U}\left(t_{s}\right)-U\right)}{\sigma_{u}}
$$

where $\hat{U}\left(t_{s}\right)$ is the maximum mean wind speed within the interval $t_{s}$. Figure 20 shows a relationship between the turbulence intensity and gust factor under different time intervals. Substituting Equation (14) into Equation (15), one can obtain the expression between the peak factor and the turbulence intensity:

$$
g_{u}\left(t_{s}\right)=k_{1} I_{u}^{k_{2}-1} \ln \left(\frac{T}{t_{g}}\right)
$$

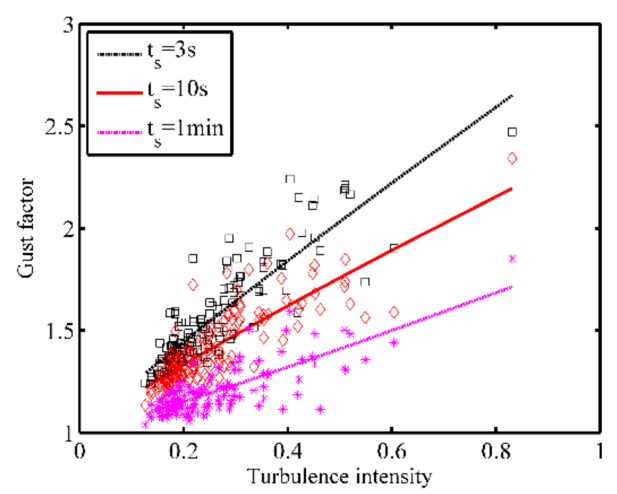

Figure 20. Relationship between the turbulence intensity and the gust factor at different time intervals.

Figures 21 and 22 show the peak factor with gust duration of $3 \mathrm{~s}$ per 10 min time interval via the wind speed and turbulence intensity, respectively. Figure 20 indicates that the peak factors slightly changed with the wind speed. The minimum, maximum, and mean values of the peak factor were 1.40,3.93, and 2.23, respectively. Compared with the results obtained by Wang [36], which were 2.43, 2.48 and 2.47 at $10 \mathrm{~m}, 20 \mathrm{~m}$ and $40 \mathrm{~m}$, respectively, the present research showed a larger maximum value but a smaller average 
value. These changes may be due to the fluctuation in the wind speed in the presented measurement site, which can also be seen by comparing the turbulence intensities.

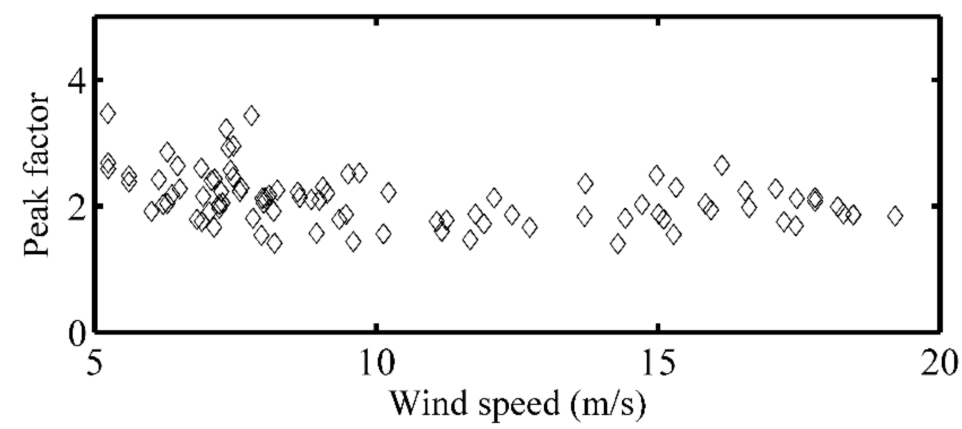

Figure 21. Peak factors at different wind speeds during Typhoon "Maria" ( $t=3 \mathrm{~s})$.

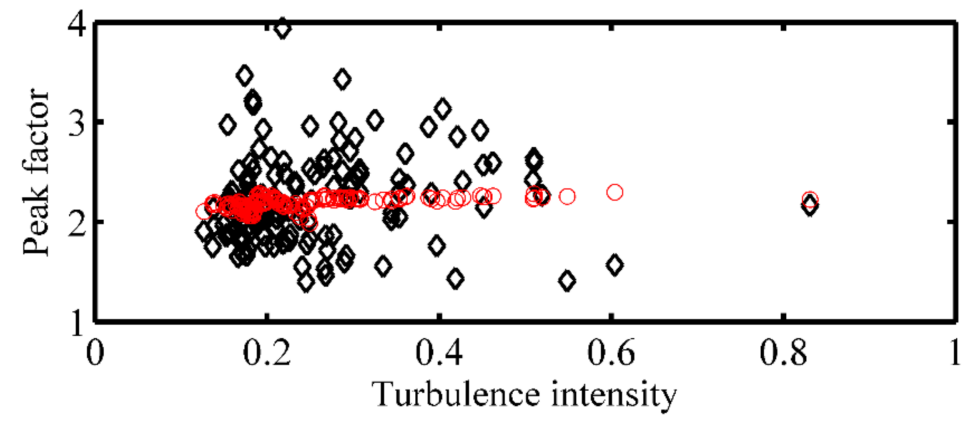

Figure 22. Peak factors with turbulence intensities during Typhoon "Maria" $(t=3 \mathrm{~s})$.

\subsubsection{Turbulence Integral Length Scale}

The turbulence integral length scale is defined as the average size of the turbulent eddies of flows, which describe the influence of the fluctuating wind on structures. Based on Taylor's assumption, the expression of the turbulence integral length scale can be defined as follows:

$$
L_{u}^{x}=\frac{U}{\sigma_{u}^{2}} \int_{0}^{R_{u}=0.05 \sigma_{u}} R_{u}(\tau) d \tau, L_{v}^{y}=\frac{U}{\sigma_{v}^{2}} \int_{0}^{R_{v}=0.05 \sigma_{v}} R_{v}(\tau) d \tau, L_{w}^{z}=\frac{U}{\sigma_{w}^{2}} \int_{0}^{R_{w}=0.05 \sigma_{w}} R_{w}(\tau) d \tau
$$

where $L_{u}^{x}, L_{v}^{y}$, and $L_{w}^{z}$ are the measured turbulence integral length scales in the longitudinal, horizontal, and vertical directions, respectively. $R_{u}(\tau), R_{v}(\tau)$, and $R_{w}(\tau)$ are the autocorrelation functions of the fluctuating wind in the longitudinal, horizontal, and vertical directions, respectively, and $\tau$ is the time difference. The equation of the autocorrelation function can be presented as in Equation (19).

$$
R(\tau)=E(X(t) X(t+\tau)),
$$

where $X(t)$ is a random wind process. Based on Equation (19), the autocorrelation coefficients of three components at different heights are presented in Figure 23. Generally, the autocorrelation coefficients decrease with time difference $\tau$; for the vertical components at height $100 \mathrm{~m}$, it was different, which agreed with the results in the literature [1]. 

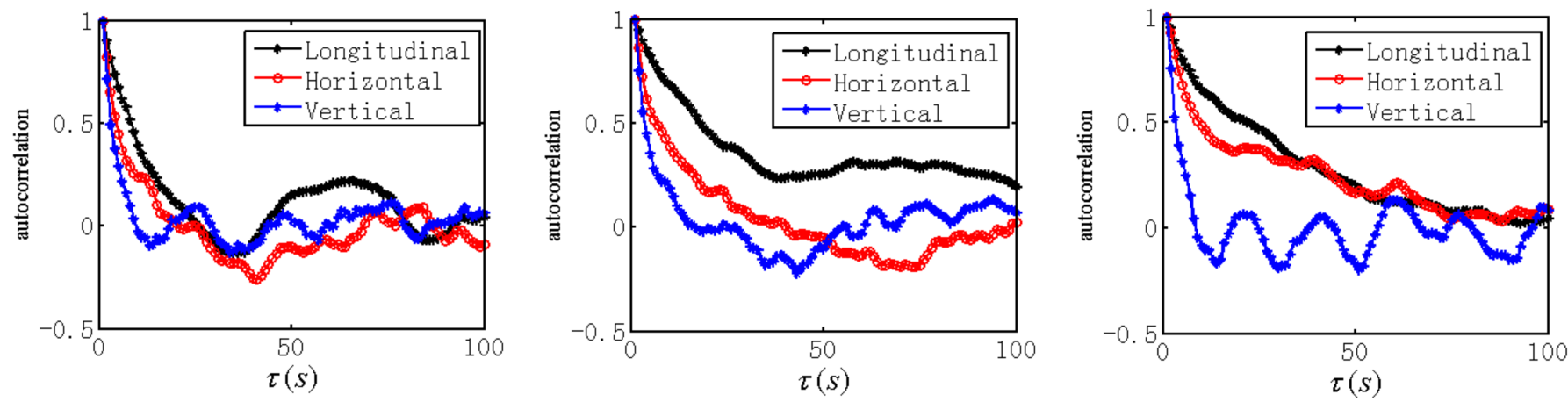

Figure 23. Autocorrelation coefficients of wind speed fluctuation components $(10 \mathrm{~m}, 80 \mathrm{~m}$, and $100 \mathrm{~m})$.

Figure 24 shows the integral length scale of Typhoon "Maria" with different speeds at three heights: $10 \mathrm{~m}, 80 \mathrm{~m}$, and $100 \mathrm{~m}$. It can be concluded that the turbulence intensity increases with height and the relation $L_{u}^{x}>L_{v}^{y}>L_{w}^{z}$. It was also observed that the integral length scale decreased with wind speed in all three directions and showed more dispersion than the turbulence intensity. The mean values of the integral length scale in the longitudinal, horizontal, and vertical directions at $10 \mathrm{~m}$ were $93.89 \mathrm{~m}, 68.24 \mathrm{~m}$, and $55.85 \mathrm{~m}$, respectively. Table 7 shows the summary of the ratio of $L_{u}^{x}: L_{v}^{y}: L_{w}^{z}$ in the literature and present research. It can be seen that the ratio between $L_{u}^{x}: L_{v}^{y}$ in this study was close to that in [36]. However, the ratio of $L_{w}^{z}$ was much larger than that in the references in the table, except in [6]. One consideration is that the terrain may significantly affect the integral length scale as the two measurement sites were both located in Pingtan County in Fujian Province, China.
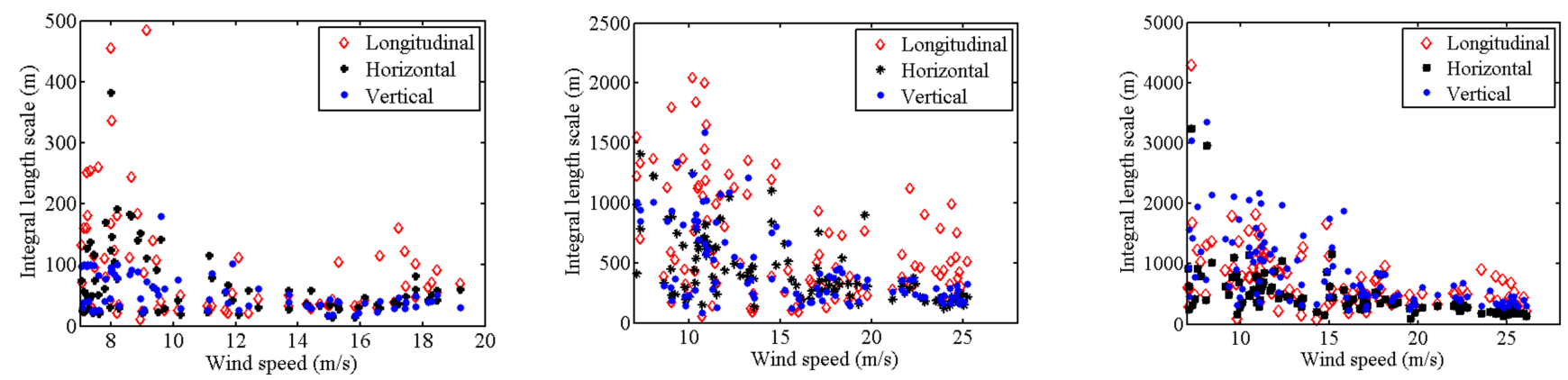

Figure 24. Integral length scale of the wind speed $(10 \mathrm{~m}, 80 \mathrm{~m}$, and $100 \mathrm{~m})$.

Table 7. Comparison of the integral length scale in the literature.

\begin{tabular}{ccccc}
\hline Typhoon & $\begin{array}{c}\text { Maximum 10 min } \\
\text { Mean Speed }\end{array}$ & Observation Height & $L_{u}^{x}: L_{v}^{y}: L_{w}^{z}$ & Location \\
Meari, 2011 [36] & & $10 \mathrm{~m}$ & $1: 0.69: 0.08$ & Zhejiang, China \\
Maemi 2003 [35] & $15.05 \mathrm{~m} / \mathrm{s}$ & $20 \mathrm{~m}$ & $1: 0.61: 0.09$ & Miyakojima, Japan \\
Muifa, 2011 [1] & $38.4 \mathrm{~m} / \mathrm{s}$ & $40 \mathrm{~m}$ & $1: 0.65: 0.13$ & Shanghai, China \\
Naseat and Hiatang, 2016 [6] & & $10 \mathrm{~m}$ & $1: 0.42: 0.18$ & Fujian, China \\
This study & $33 \mathrm{~m} / \mathrm{s}$ & $20 \mathrm{~m}$ & $1: 0.65: 0.11$ & Fujian, China \\
\hline
\end{tabular}




\subsubsection{Cross-Correlations and Coherence}

The cross-correlations show the correlation between fluctuating wind components, which can be expressed as follows:

$$
C_{R(i j)}=\frac{R_{i j}(0)}{\sqrt{R_{i i}(0)} \sqrt{R_{j j}(0)}}
$$

where $C_{R(i j)}$ is the cross-correlation coefficient of the fluctuating wind component of $I$ and $j$; $R_{i j}$ is the corresponding cross-correlation coefficient; and $R_{i i}$ and $R_{i j}$ are the autocorrelation of the fluctuating wind components of $i$ and $j$, respectively.

Figures 25 and 26 show the cross-correlation coefficients between the fluctuation wind speeds at heights of 10 and $80 \mathrm{~m}$, respectively. Figures $25 \mathrm{a}-\mathrm{c}$ and $26 \mathrm{a}-\mathrm{c}$ show the coefficients between the $u, v$ direction, $u, w$ direction, and $v, w$ direction, respectively. It can be concluded from Figures 25 and 26 that the correlations between $u$ and $v, v$ and $w$ were approximately 0 , which showed good agreement with the results in [1]. However, the fluctuation wind speed in the $v$ and $w$ directions showed a negative correlation with the coefficients -0.36 and -0.26 , respectively, as seen in Figures $25 b$ and $26 b$, which was comparable to the results in the neutral surface boundary layer of -0.3 [1].

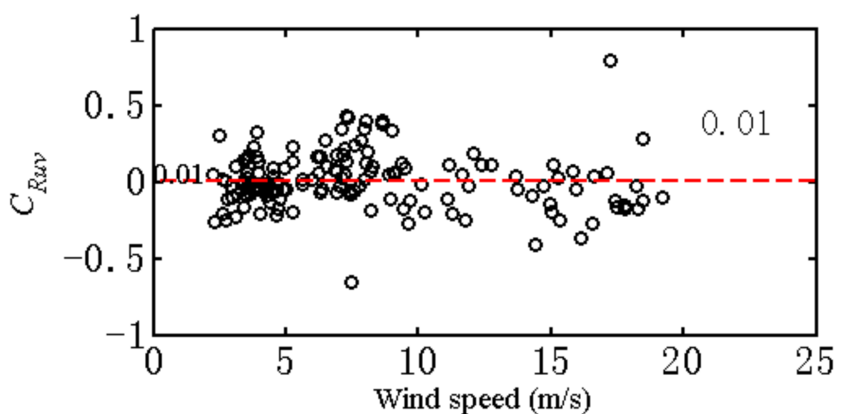

(a)

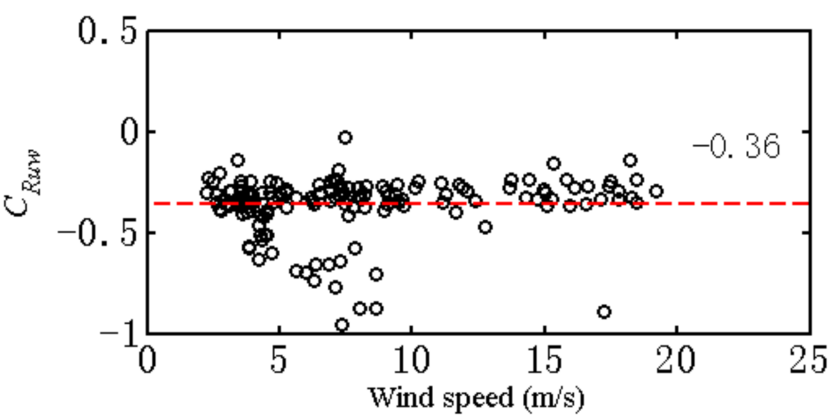

(b)

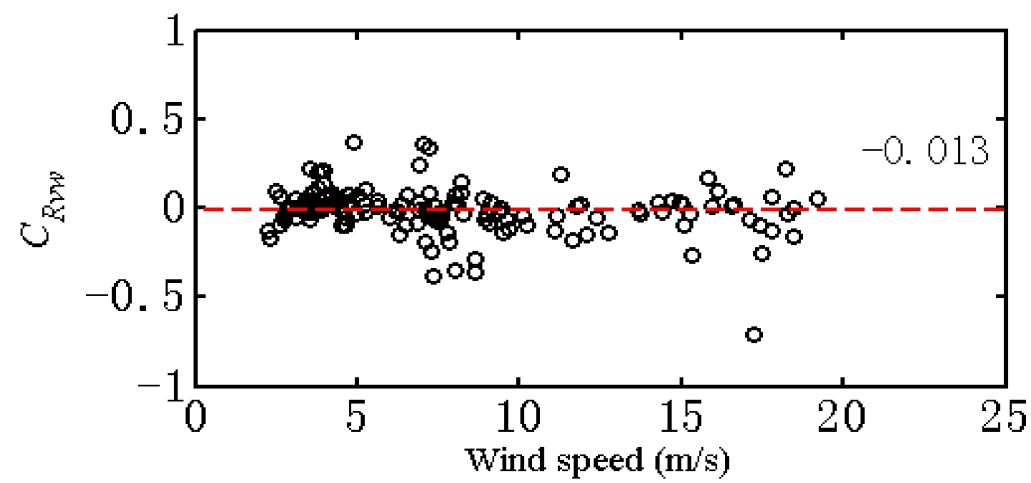

(c)

Figure 25. Correlation between the fluctuation wind speed at $10 \mathrm{~m}$. (a) $u$ and $v$ directions; (b) $u$ and $w$ directions; and (c) $v$ and $w$ directions. 


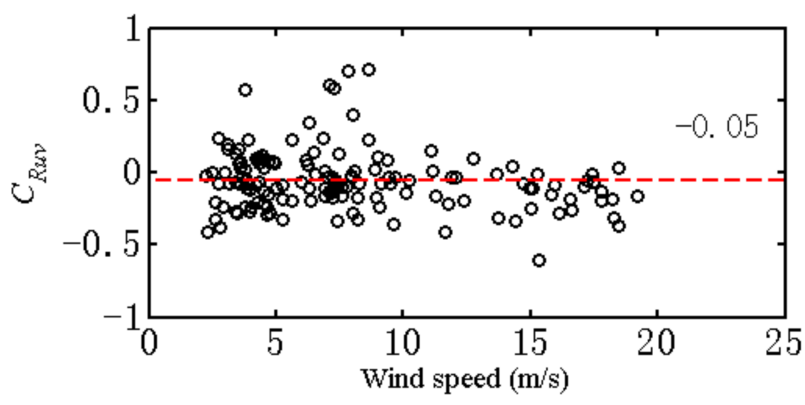

(a)

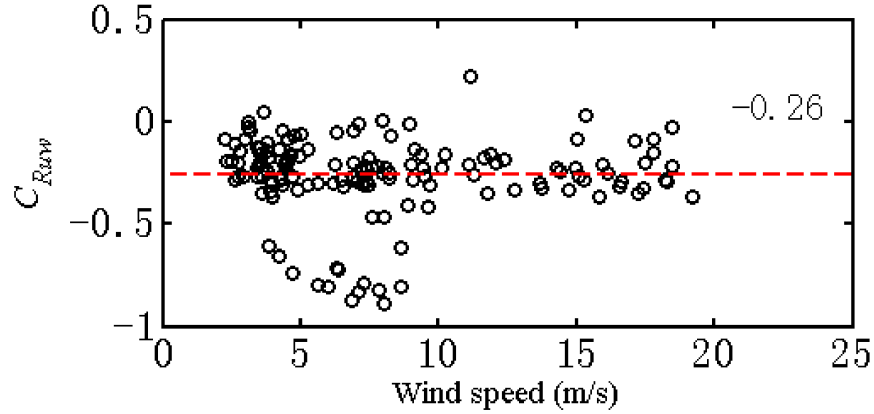

(b)

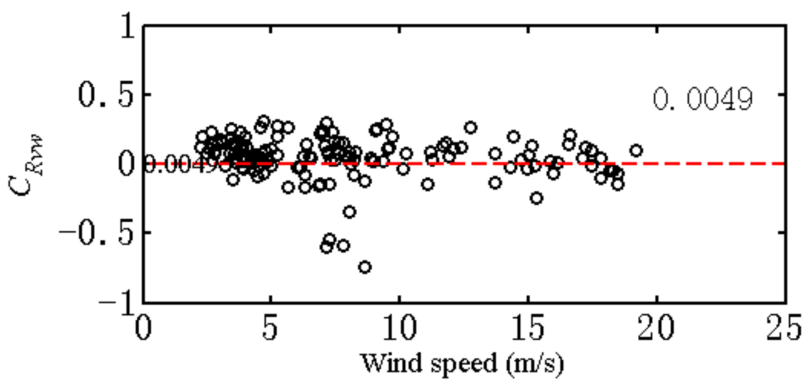

(c)

Figure 26. Correlation between the fluctuation wind speed at $80 \mathrm{~m}$. (a) $u$ and $v$ directions; (b) $u$ and $w$ directions; and (c) $v$ and $w$ directions.

The coherence model was developed by Davenport in 1961 to describe the correlation among the frequency domain, which is used as an exponential decaying model:

$$
\operatorname{coh}(f)=\exp \left(-\frac{f}{U}\left(C_{x}^{2} \Delta x^{2}+C_{y}^{2} \Delta y^{2}+C_{z}^{2} \Delta z^{2}\right)^{1 / 2}\right)
$$

where $f$ is the frequency; $U$ is the mean wind speed; $C_{y}$ and $C_{z}$ are the exponential decay coefficients in the lateral and vertical directions, respectively; and $\Delta y$ and $\Delta z$ are the distances between two measured points in the lateral and vertical directions, respectively. In this experiment, the distance in the lateral direction was 0 , and then the decay model can be expressed as follows:

$$
\operatorname{coh}(f)=\exp \left(-C_{z} \frac{f \Delta z}{U}\right)
$$

Figures 25-27 show the coherence at different wind speeds in the three directions. It can be seen that the decay coefficient increased with increasing wind speed in all directions, which agreed with the results in the literature [1]. Comparing Figures 27-29, the coherence coefficient in the $v$ and $w$ directions can be better fitted than that in the $u$ direction by the exponential decay model.
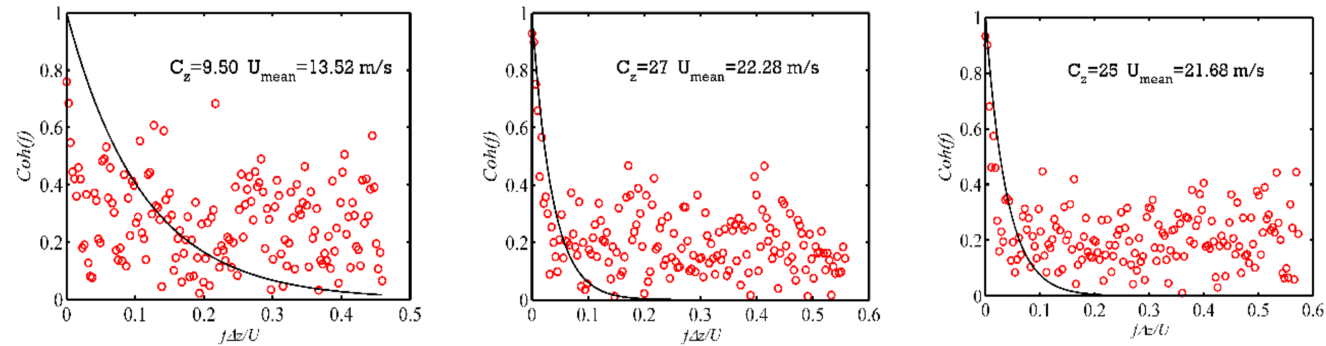

Figure 27. Coherence function at different wind speeds in the $u$ direction. 

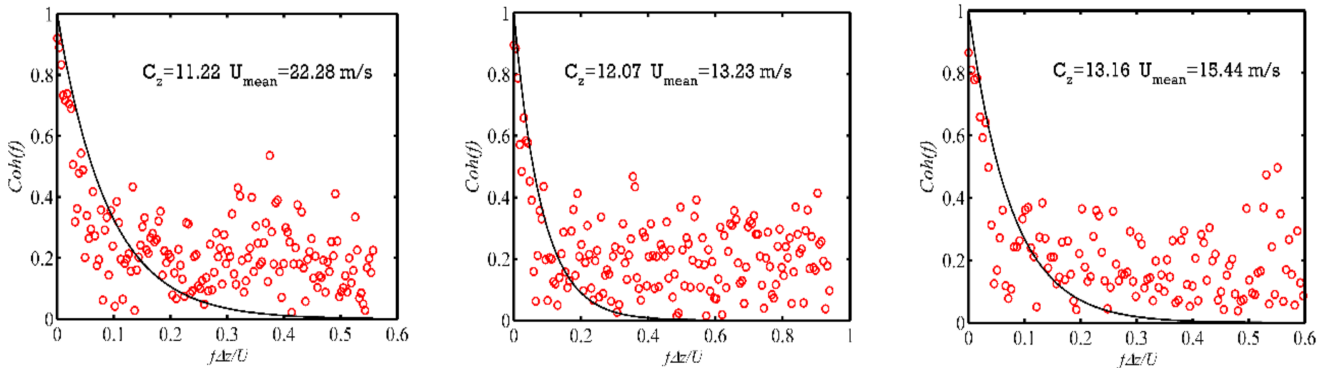

Figure 28. Coherence function at different wind speeds in the $v$ direction.
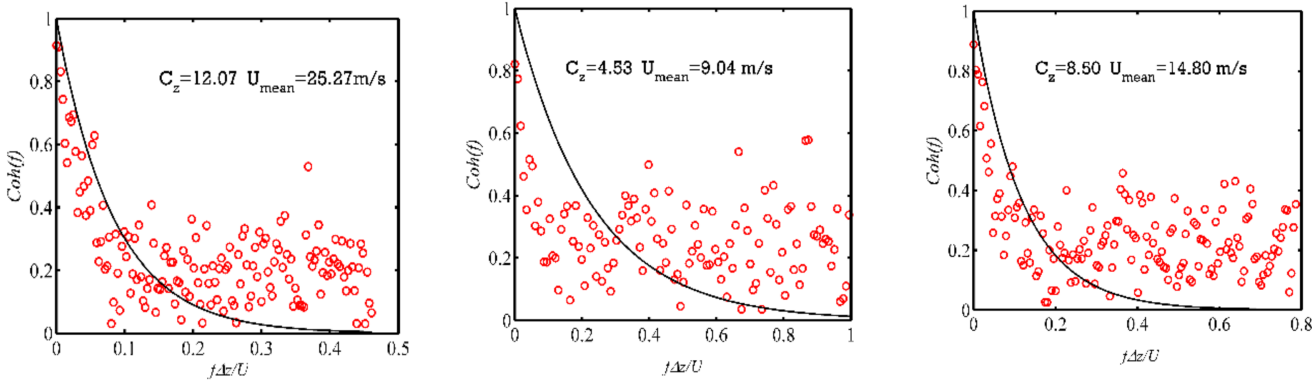

Figure 29. Coherence function at different wind speeds in the $w$ direction.

\subsection{Power Spectrum Density (PSD) Function}

The distribution of the fluctuating wind energy with respect to frequency, described as the power spectrum density (PDS), is significant for predicting wind loading on structures and the corresponding response. Low-frequency or larger eddies may dominate the wind energy, and high-frequency or lower eddies may be ignored in the wind load analysis. The descriptions of the PSD by the Karman model are expressed as follows [37,38]:

Longitudinal direction:

$$
\frac{n S(n)}{u_{*}^{2}}=\frac{4 \beta f}{\left(1+70.8 f^{2}\right)^{5 / 6}}
$$

Horizontal and vertical directions:

$$
\frac{n S(n)}{u_{*}^{2}}=\frac{4 \beta f\left(1+755.2 f^{2}\right)}{\left(1+283.2 f^{2}\right)^{11 / 6}}
$$

where $f=\frac{n L_{u}^{x}}{U}, L_{u}^{x}$ is the turbulence integral scale; $U$ is the mean wind; $\beta$ is the coefficient of the friction velocity; $\sigma_{u}^{2}=\beta u_{*}^{2}$; and $\sigma_{u}$ is the variance of the fluctuating wind speed components.

The Davenport spectrum, which is recommended in the Chinese Code, has also been widely used for modeling the longitudinal wind direction. The expression is described as follows:

$$
\frac{n S(z, n)}{u_{*}^{2}}=\frac{4 f^{2}}{(1+f)^{4 / 3}}
$$

where $f=\frac{1200 n}{U(10)}$ and $U(10)$ is the mean wind speed at a height of $10 \mathrm{~m}$.

The Panofsky model has been widely used for the calculation of the power spectrum for the vertical wind speed component with the following expression [39]:

$$
\frac{n S(z, n)}{u_{*}^{2}}=\frac{6 f}{(1+4 f)^{2}}
$$


Figure 30 shows the wind power spectra during Typhoon "Maria" in the longitudinal wind direction at time intervals of $10 \mathrm{~min}, 20 \mathrm{~min}$, and $60 \mathrm{~min}$. It can be seen that the general tendency for the wind spectra at time intervals were similar. However, for the larger time interval, the amplitudes at high frequency were larger. As the time interval of $10 \mathrm{~min}$ is recommended in the wind-resist design standard in China, the following analysis was based on a time interval of $10 \mathrm{~min}$.

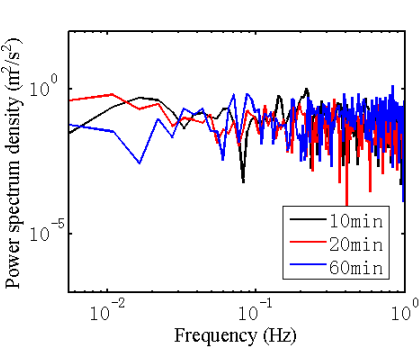

(a)

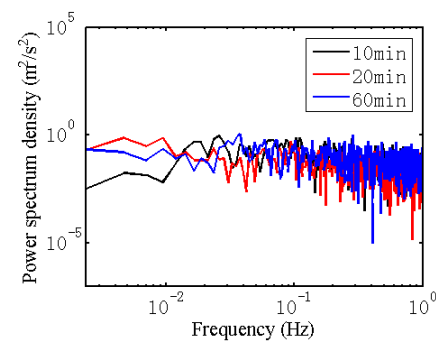

(b)

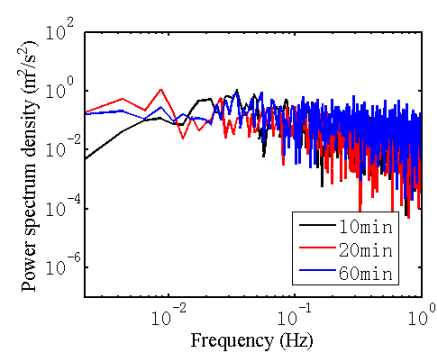

(c)

Figure 30. Power spectra of the longitudinal wind component for different time interval at (a) $10 \mathrm{~m}$, (b) $80 \mathrm{~m}$, and (c) $100 \mathrm{~m}$.

Figure 31 shows the wind power spectra during Typhoon "Maria" in the longitudinal wind direction. The measured power spectra were compared with the spectra of the Karman and Davenport models. It can be concluded that the Karman model can be fitted better than the Davenport model in the longitudinal direction, even though the Davenport spectrum shows better fitting performance in the high-frequency area. The measured vertical spectra were fitted by the Karman model and Panofsky model as shown in Figure 32. Comparing the two models, the Panofsky model showed better results in the fitting of the measured wind spectrum at lower frequencies at a $10 \mathrm{~m}$ height. However, for heights of $80 \mathrm{~m}$ and $100 \mathrm{~m}$, the measured wind spectra agreed well with the Panofsky model at both high and low frequencies.

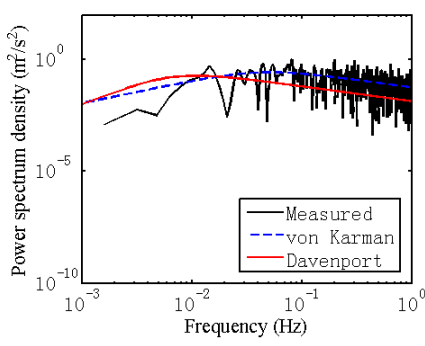

(a)

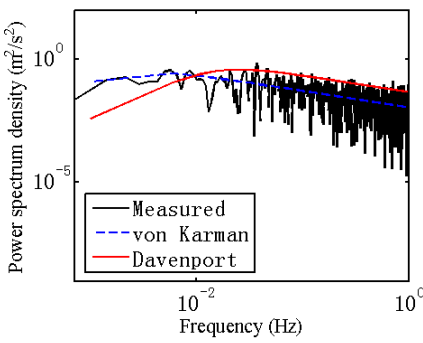

(b)

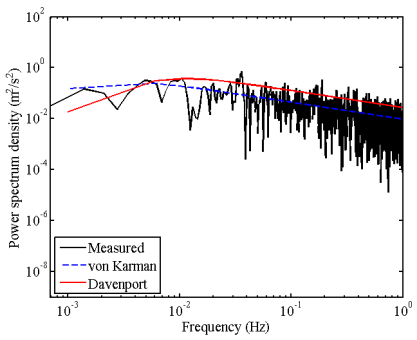

(c)

Figure 31. Power spectra of the longitudinal wind component at (a) $10 \mathrm{~m}$, (b) $80 \mathrm{~m}$, and (c) $100 \mathrm{~m}$.

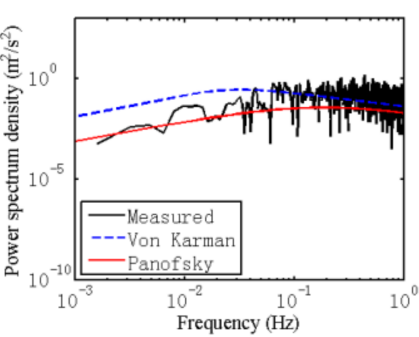

(a)

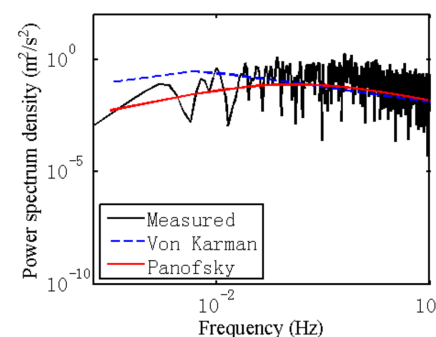

(b)

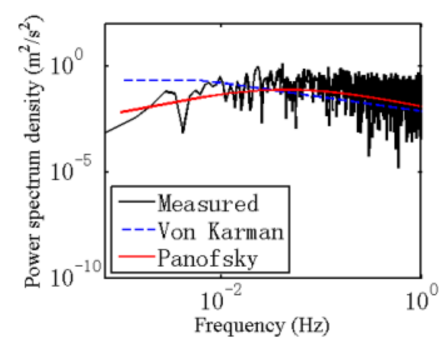

(c)

Figure 32. Power spectra of the vertical wind component at (a) $10 \mathrm{~m},(\mathbf{b}) 80 \mathrm{~m}$, and (c) $100 \mathrm{~m}$. 
According to the Kolmogorov turbulence theory, the fluctuating wind power spectra can be expressed by the following empirical expression:

$$
\frac{n S(n)}{\sigma_{u}^{2}}=\frac{A f^{\alpha \beta-2 / 3}}{\left(1+B f^{\alpha}\right)^{\beta}}
$$

where $\sigma_{u}^{2}$ is the variance of the longitudinal wind component; $A, B, \alpha$, and $\beta$ are the coefficients that need to be fitted; and $f$ is the converted frequency. The fitted power spectrum can be seen in the Figure 33.

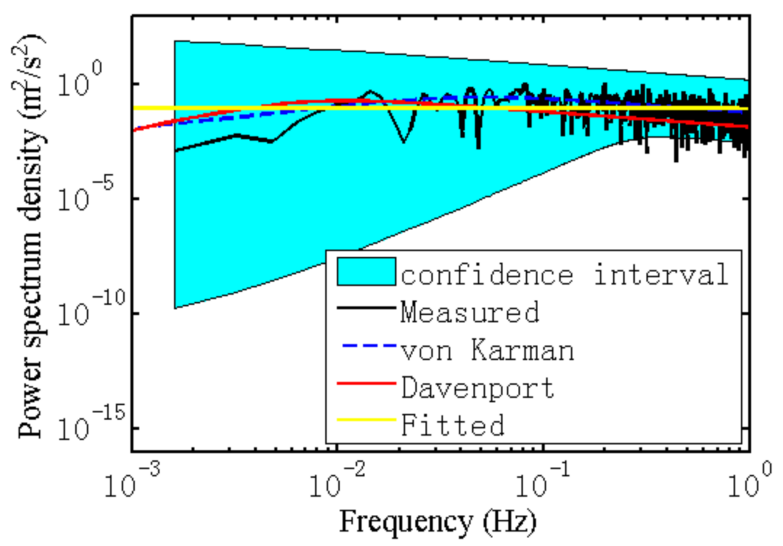

Figure 33. Power spectra of the longitudinal wind component at $10 \mathrm{~m}$.

The fitted value of the empirical expression can be obtained in the following Table 8:

Table 8. Fitted values by empirical expression at $10 \mathrm{~m}$.

\begin{tabular}{cccc}
\hline$A$ & $\boldsymbol{B}$ & $\boldsymbol{\alpha}$ & $\beta$ \\
\hline 0.0932 & 2.4364 & 0.2736 & 0.2717 \\
\hline
\end{tabular}

\section{Conclusions}

The wind characteristics of the periphery of Typhoon "Maria" were studied in this research on the basis of the observed wind speed data recorded from sonic anemometers on a $100 \mathrm{~m}$ tower. Based on the analysis results, the following conclusions can be summarized:

(1) The field measurement was conducted with the applications of both ultrasonic and vane-type anemometers, and wind data of the periphery of Typhoon "Maria" were therefore recorded.

(2) Data control methods were applied to filter the high frequency wind data to obtain more reasonable data for analysis.

(3) The reliability of the obtained sonic wind speed data was guaranteed by a comparison of the mean wind speed between the data from sonic anemometers and vane anemometers.

(4) The wind profile parameter calculated by the power law was 0.2208 , which was larger than that recommended in the Chinese Code; the wind profile parameter decreased with increasing wind speed.

(5) The turbulence intensity decreased with increase in wind speed. The gust factor showed a linear relation with the logarithm of the time interval in both the longitudinal, horizontal, and vertical directions.

(6) Based on the statistical characteristics, the turbulence intensity and gust factor followed a Type II GEV distribution. The gust factor decreases with an increasing time interval and has a linear relationship with the logarithm of the time interval. The maximum and mean values of the peak factor during Typhoon "Maria" were 
3.93 and 2.23, respectively. The fitted parameter of the relationship between the gust factor and turbulence intensity was comparably studied.

(7) The turbulence integral length scale of the periphery of Typhoon "Maria" $L_{u}^{x}: L_{v}^{y}: L_{w}^{z}=1: 0.72: 0.59$, the ratio of the vertical component was larger than that in the literature but close to those of Typhoons Naseat and Hiatang, which also occurred in Fujian Province.

(8) The correlations between $u$ and $v, v$ and $w$ were approximately 0 , which showed good agreement with the results in the literature, and the fluctuation wind speed in the $v$ and $w$ directions showed a negative correlation. The decay coefficient increased with increasing wind speed in all directions, and the decay model could be better fitted better in the $v$ and $w$ directions.

(9) The power spectrum of this typhoon can be expressed by the Karman spectrum; for the vertical spectrum, it agreed well with the Panofsky model at higher frequency.

Author Contributions: Conceptualization, D.X., L.D. and L.L.; methodology, D.X., L.D. and L.L.; experiment, D.X., L.D. and L.L., H.W. and H.H.; data analysis: D.X., H.W. and H.H.; writing: D.X. and L.D.; supervision, L.D. and L.L. All authors have read and agreed to the published version of the manuscript.

Funding: This research was funded by Fujian provincial project of Transportation Science and Technology (201903), Wind Engineering Service Platform of Xiamen (No. 3502Z20161016), Natural Sciences and Engineering Research Council of Canada (NSERC), the industry-university cooperation project of Fujian Province (2020H6022), Natural Sciences Foundation of Fujian Province (2020J01275), and the financial support of the Chinese Scholarship Council (CSC).

Conflicts of Interest: The authors declare no conflict of interest.

\section{References}

1. Wang, X.; Huang, C.; Huang, P.; Yu, X. Study on wind characteristics of a strong typhoon in near-ground boundary layer. Struct. Des. Tall Spec. Build. 2016, 26, e1338. [CrossRef]

2. Song, L.; Li, Q.S.; Chen, W.; Qin, P.; Huang, H.; He, Y.C. Wind characteristics of a strong typhoon in marine surface boundary layer. Wind Struct. 2012, 15, 1-15. [CrossRef]

3. Choi, E.C. Wind characteristics of tropical thunderstorms. J. Wind Eng. Ind. Aerodyn. 2000, 84, 215-226. [CrossRef]

4. Wang, Z.; Zhao, Y.; Li, F.; Jiang, J. Extreme Dynamic Responses of MW-Level Wind Turbine Tower in the Strong Typhoon Considering Wind-Rain Loads. Math. Probl. Eng. 2013, 2013, 512530. [CrossRef]

5. Xu, Y.L.; Zhan, S. Field measurements of Di Wang Tower during Typhoon York. J. Wind Eng. Ind. Aerodyn. 2001, 89, 73-93. [CrossRef]

6. Lin, L.; Chen, K.; Xia, D.; Wang, H.; Hu, H.; He, F. Analysis on the wind characteristics under typhoon climate at the southeast coast of China. J. Wind Eng. Ind. Aerodyn. 2018, 182, 37-48. [CrossRef]

7. Law, S.S.; Bu, J.Q.; Zhu, X.Q.; Chan, S.L. Wind characteristics of Typhoon Dujuan as measured at a 50m guyed mast. Wind Struct. 2006, 9, 387-396. [CrossRef]

8. Song, L.; Chen, W.; Wang, B.; Zhi, S.; Liu, A. Characteristics of wind profiles in the landfalling typhoon boundary layer. J. Wind Eng. Ind. Aerodyn. 2016, 149, 77-88. [CrossRef]

9. Wang, H.; Xu, Z.; Wu, T.; Mao, J. Evolutionary power spectral density of recorded typhoons at Sutong Bridge using harmonic wavelets. J. Wind Eng. Ind. Aerodyn. 2018, 177, 197-212. [CrossRef]

10. Li, L.; Zhou, Y.; Wang, H.; Zhou, H.; He, X.; Wu, T. An Analytical Framework for the Investigation of Tropical Cyclone Wind Characteristics over Different Measurement Conditions. Appl. Sci. 2019, 9, 5385. [CrossRef]

11. Chen, J.; Hui, M.C.H.; $\cdot \mathrm{Xu}, \mathrm{Y}$. A comparative study of stationary and non-stationary wind models using field measurements. Bound. Layer Meteorol. 2007, 122, 105-121. [CrossRef]

12. Wang, H.; Wu, T.; Tao, T.; Li, A.; Ahsan, K. Measurements and analysis of non-stationary wind characteristics at Sutong Bridge in Typhoon Damrey. J. Wind Eng. Ind. Aerodyn. 2016, 151, 100-106. [CrossRef]

13. Tao, T.; Wang, H.; Wu, T. Comparative Study of the Wind Characteristics of a Strong Wind Event Based on Stationary and Nonstationary Models. J. Struct. Eng. 2016, 143, 04016230. [CrossRef]

14. Li, Q.S.; Xiao, Y.Q.; Wong, C.K. Full-scale monitoring of typhoon effects on super tall buildings. J. Fluids Struct. 2005, 20, 697-717. [CrossRef]

15. Fu, J.Y.; Li, Q.S.; Wu, J.R.; Xiao, Y.Q.; Song, L.L. Field measurements of boundary layer wind characteristics and wind-induced responses of super-tall buildings. J. Wind Eng. Ind. Aerodyn. 2008, 96, 1332-1358. [CrossRef]

16. Yi, J.; Zhang, J.W.; Li, Q.S. Dynamic characteristics and wind-induced responses of a super-tall building during typhoons. J. Wind Eng. Ind. Aerodyn. 2013, 121, 116-130. [CrossRef]

17. Li, Q.S.; Xiao, Y.Q.; Wu, J.R.; Fu, J.Y.; Li, Z.N. Typhoon effects on super-tall buildings. J. Sound Vib. 2008, 313, 581-602. [CrossRef] 
18. Wang, H.; Li, A.; Guo, T.; Xie, J. Field measurement on wind characteristic and buffeting response of the Runyang Suspension Bridge during typhoon Matsa. Sci. China 2009, 52, 1354-1362. [CrossRef]

19. Xu, Y.L.; Zhu, L.D.; Wong, K.Y.; Chan, K.W.Y. Field measurement results of Tsing Ma suspension Bridge during Typhoon Victor. Struct. Eng. Mech. 2000, 10, 545-559. [CrossRef]

20. Wang, H.; Li, A.; Niu, J.; Zong, Z.; Li, J. Long-term monitoring of wind characteristics at Sutong Bridge site. J. Wind Eng. Ind. Aerodyn. 2013, 115, 39-47. [CrossRef]

21. Song, L.; Pang, J.; Jing, C.; Huang, H.; Qin, P. Field measurement and analysis of turbulence coherence for Typhoon Nuri at Macao Friendship Bridge. Sc. China 2010, 53, 2647-2657. [CrossRef]

22. Chang, T.-P.; Ko, H.-H.; Liu, F.-J.; Chen, P.-H.; Chang, Y.-P.; Liang, Y.-H.; Jang, H.-Y.; Lin, T.-C.; Chen, Y.-H. Fractal dimension of wind speed time series. Appl. Energy 2012, 93, 742-749. [CrossRef]

23. Shu, Z.; Li, Q.S.; Chan, P.W. Statistical analysis of wind characteristics and wind energy potential in Hong Kong. Energy Convers. Manag. 2015, 101, 644-657. [CrossRef]

24. Akdag, S.A.; Dinler, A. A new method to estimate Weibull parameters for wind energy applications. Energy Convers. Manag. 2009, 50, 1761-1766. [CrossRef]

25. Carta, J.A.; Ramirez, P.; Velazquez, S. A review of wind speed probability distributions used in wind energy analysis: Case studies in the Canary Islands. Renew. Sustain. Energy Rev. 2009, 13, 933-955. [CrossRef]

26. Chang, T.P. Estimation of wind energy potential using different probability density functions. Appl. Energy 2011, 88, 1848-1856 [CrossRef]

27. Shikhovtsev, A.; Kovadlo, P.; Lukin, V.; Victor, N.; Alexander, K.; Dmitry, K.; Evgeny, K.; Shikhovtsev, M.; Fedor, A. Statistics of the Optical Turbulence from the Micrometeorological Measurements at the Baykal Astrophysical Observatory Site. Atmosphere 2019, 10, 661. [CrossRef]

28. Victor, N.; Vladimir, L.; Eugene, N.; Andrei, T.; Aleksandr, B. Measurement of Atmospheric Turbulence Characteristics by the Ultrasonic Anemometers and the Calibration Processes. Atmosphere 2019, 10, 460. [CrossRef]

29. Lin, L.; Chen, K.; Xia, D.; Wang, H.; Hu, H.; He, F. Measurement of wind field data in Southeast China. Data Brief 2018, 21, 328-333. [CrossRef]

30. Li, G. Design Principles of Load and Reliability of Engineering Structures, 2nd ed.; China Construction Industry Press: Beijing, China, 2001.

31. Fang, G.; Zhao, L.; Cao, S.; Ge, Y.; Li, K. Gust characteristics of near-ground typhoon winds. J. Wind Eng. Ind. Aerodyn. 2019, 188, 323-337. [CrossRef]

32. Shu, Z.R.; Li, Q.S.; He, Y.C.; Chan, P.W. Gust factors for tropical cyclone, monsoon and thunderstorm winds. J. Wind Eng. Ind. Aerodyn. 2015, 142, 1-14. [CrossRef]

33. Ishizaki, H. Wind profiles, turbulence intensities and gust factors for design in typhoon-prone regions. J. Wind Eng. Ind. Aerodyn. 1983, 13, 55-66. [CrossRef]

34. Choi, C.-C. Wind Loading in Hong Kong: Commentary on the Code of Practice on Wind Effects Hong Kong, 1983; Hong Kong Institute of Engineers: Hong Kong, China, 1984.

35. Cao, S.; Tamura, Y.; Kikuchi, N.; Saito, M.; Nakayama, I.; Matsuzaki, Y. Wind characteristics of a strong typhoon. J. Wind Eng. Ind. Aerodyn. 2009, 97, 11-21. [CrossRef]

36. Wang, X.; Huang, P.; Yu, X.; Wang, X.; Liu, H. Wind characteristics near the ground during typhoon Meari. J. Zhejiang Univ. Sci. A 2017, 18, 33-48. [CrossRef]

37. Li, Q.S.; Li, X.; He, Y. Monitoring Wind Characteristics and Structural Performance of a Supertall Building during a Landfall Typhoon. J. Struct. Eng. 2016, 142, 04016097. [CrossRef]

38. Von Karman, T. Progress in the statistical theory of turbulence. Proc. Natl. Acad. Sci. USA 1948, 34, 530-539. [CrossRef]

39. Panofsky, H.A.; Mccormick, R.A. The spectrum of vertical velocity near the surface. Q. J. R. Meteorol. Soc. 1960, 86, 495-503. [CrossRef] 